\title{
Culture and Group Perception: Dispositional and Stereotypic Inferences About Novel and National Groups
}

\author{
Julie Spencer-Rodgers \\ University of Victoria \\ David L. Hamilton \\ University of California, Santa Barbara
}

\author{
Melissa J. Williams \\ University of California, Berkeley \\ Kaiping Peng \\ University of California, Berkeley
}

\author{
Lei Wang \\ Peking University
}

\begin{abstract}
In 3 studies, the authors tested the hypothesis that Chinese participants would view social groups as more entitative than would Americans and, as a result, would be more likely to infer personality traits on the basis of group membership - that is, to stereotype. In Study 1, Chinese participants made stronger stereotypic trait inferences than Americans did on the basis of a target's membership in a fictitious group. Studies 2 and 3 showed that Chinese participants perceived diverse groups as more entitative and attributed more internally consistent dispositions to groups and their members. Guided by culturally based lay theories about the entitative nature of groups, Chinese participants may stereotype more readily than do Americans when group membership is available as a source of dispositional inference.
\end{abstract}

Keywords: entitativity, stereotypes, dispositional inference, cross-cultural differences, Chinese cultural groups

Recent cross-cultural work, particularly research comparing members of East Asian and Western cultures, has revealed striking differences in cognition, emotion, and behavior (e.g., Choi, Nisbett, \& Norenzayan, 1999; Kashima, Siegal, Tanaka, \& Kashima, 1992), as well as fascinating similarities in underlying psychological processes and motives (e.g., attribution for group vs. individual behavior; Menon, Morris, Chiu, \& Hong, 1999; and cognitive dissonance; Hoshino-Browne, Zanna, \& Spencer, 2005). Stereotyping processes, however, have been the focus of relatively little

Julie Spencer-Rodgers, Department of Psychology, University of Victoria, Victoria, British Columbia, Canada; Melissa J. Williams and Kaiping Peng, Department of Psychology, University of California, Berkeley; David L. Hamilton, Department of Psychology, University of California, Santa Barbara; Lei Wang, Department of Psychology, Peking University, Beijing, China.

This research was supported by grants awarded to Julie SpencerRodgers from the National Science Foundation, International Programs Office, and the University of California Institute of Global Cooperation and Conflict. We thank Yoshihisa Kashima, Molly Parker Tapias, Susannah Paletz, Maria Logli Allison, Tammy English, Adam Cohen, and Diane Velasco for their invaluable comments on drafts of this article. We also thank Eva Liao and Xiang Yao for their assistance with data collection and translation in China, and we thank Jane Lee, Reza Asgari, Erol Ari, Wayne Chan, Kate Dong, Xiao He, Jung Yun Jang, Antje Schumacher, Christina Qi, William Tov, Karin Voelker, Lawrence Wan, and Jo Wu for their assistance with data collection and translation in the United States.

Correspondence concerning this article should be addressed to Julie Spencer-Rodgers, Department of Psychology, University of Victoria, Victoria, British Columbia V8W 3P5, Canada. E-mail: jrodgers@uvic.ca cross-cultural investigation. Despite a vast literature on the content of stereotypic beliefs about national and racial/ethnic groups around the world (see Fiske, 1998; Fiske, Cuddy, Glick, \& Xu, 2002), it is surprising that both the cross-cultural and stereotyping literatures have been largely silent on the question of whether there is cultural variation in basic stereotyping processes. For instance, little is known about whether members of East Asian cultures stereotype more or less than do members of Western cultures and, if so, whether the antecedents and consequences of stereotyping are culture-specific or universal.

On the basis of previous work in the domain of culture and causal attribution, one might guess that East Asians (in this case, mainland Chinese) would be less vulnerable to stereotyping than would Westerners (Americans). Whereas members of Western cultures have been shown to underutilize available situational information in explaining the actions of others (Ross, 1977), members of East and South Asian cultures (particularly China, Japan, Korea, and India) have been reliably shown to be more context-dependent and to place relatively greater weight on situational factors when making causal attributions. For example, they are less likely to commit the fundamental attribution error (Choi et al., 1999; F. Lee, Hallahan, \& Herzog, 1996; Miller, 1984; Morris \& Peng, 1994) and are less prone to the correspondence bias (Kashima et al., 1992). Because East Asians are more inclined to take contextual factors into account, one might speculate that Chinese participants would be less likely to explain behavior in terms of category memberships than would Americans.

Of course, causal attribution and stereotyping are distinct phenomena: Attribution involves generating a causal explanation for a 
person's behavior, whereas stereotyping involves ascribing a personality trait to an entire category of individuals (e.g., "Asians are good at math") and subsequently inferring personality traits on the basis of category membership (e.g., "Isaac is Asian; therefore, he is good at math"). Attributing causes and ascribing dispositions are different psychological mechanisms, and stereotyping does not necessarily involve attributional analysis (Hamilton, 1988, 1998). Therefore, cultural differences in causal attribution may not be a solid foundation for understanding cultural variation in stereotyping.

A number of findings imply that Chinese participants might instead be more likely to see social groups as possessing coherent dispositions or personalities. East Asians, and especially mainland Chinese, hold more collectivist values (Bond, 1986; Oyserman, Coon, \& Kemmelmeier, 2002; Triandis, 1995), perceive social groups as having greater agency (Menon et al., 1999), and may view social groups as more cohesive and homogeneous entities, relative to Americans. As a consequence, Chinese might be more inclined than Americans to perceive collections of individuals as having unique dispositions, referred to hereafter as group-level stereotyping. Moreover, in the absence of salient contextual or individuating information, they might be more likely to infer that individuals possess the personality traits that are characteristic of their social groups, referred to hereafter as individual-level stereotyping. This is often the state of affairs in everyday social perception: People frequently must make quick and imperfect social judgments without access to contextual or individuating information. Under these circumstances, it is possible that Chinese would stereotype more than Americans would, in keeping with their implicit beliefs about the entitative nature of social groups.

In the research reported here, we tested these two competing hypotheses concerning the prevalence of stereotyping among Chinese and American participants and examined a hypothesized mechanism that might give rise to cultural differences in stereotyping, specifically the perception of group entitativity. To our knowledge, these studies are the first to directly investigate these questions. In the following sections, we review the culturally relevant literature on stereotyping, dispositional thinking, and group entitativity and then report the results of three studies.

\section{Culture and Stereotyping}

The literature on stereotyping phenomena around the world has focused almost exclusively on the content of ingroup and outgroup stereotypes among a wide variety of national and racial/ethnic groups. These groups include Americans and Hong Kong Chinese (Bond, 1986), Latin Americans (Marín \& Salazar, 1985), residents of English-speaking countries (McAndrew et al., 2000), Western Europeans (Koomen \& Bähler, 1996), and Eastern Europeans (Poppe, 2001), among others. In these studies, members of each cultural group described their ingroup and the relevant outgroup(s) in terms of personality traits. Several common themes have emerged from this research: high levels of ingroup favoritism, a high degree of consensus in outgroup stereotype content among raters from multiple countries, and recurring patterns of stereotype content among pairs of nations with relations characterized by conflict or tension. This literature fits appropriately within recent models that focus on understanding the origins of stereotype content across groups, demonstrating that specific stereotypes emerge reliably from particular relationships between ingroups and outgroups (Alexander, Brewer, \& Hermann, 1999; Fiske et al., 2002). These models allow researchers to predict, for example, which specific stereotypes two cultural groups will hold of each other on the basis of the degree of resource competition between the groups, or which stereotypes majority-group members will hold of minority groups within their culture on the basis of the degree of status inequity between the groups.

What remains unresolved, however, is whether culture affects the readiness with which and the circumstances under which people use stereotypes, independent of intergroup relationships. Members of different cultures might draw disparate inferences about the same social group and its members, not only because they vary in their relationships with the group, but also because they hold fundamentally different lay beliefs about the nature and function of groups, particularly on the dimension of entitativity. Entitativity refers to the quality of "groupness" or the extent to which social aggregates come to be bona fide groups, rather than mere collections of individuals (Hamilton, Sherman, \& Castelli, 2002; Yzerbyt, Judd, \& Corneille, 2004; Yzerbyt, Rocher, \& Schadron, 1997). A further distinction can be drawn between ontological and epistemological entitativity (Kashima, 2004; Kashima et al., 2004). ${ }^{1}$ Because social groups are, in fact, more cohesive and stable in East Asian societies, East Asian lay beliefs about the nature of social groups might emphasize these group properties. We next consider the culturally relevant literature on dispositional thinking, ontological entitativity, and epistemological entitativity and outline how they might be linked to stereotyping.

\section{Culture, Dispositional Thinking, and Ontological Entitativity}

As described previously, a strong tradition in cross-cultural research has demonstrated a tendency for Westerners to make greater use of dispositional information, relative to East Asians. Westerners (Australians and Italians) are also more likely to use traits and adjectives in their open-ended descriptions of social objects than are East Asians (Koreans and Japanese; Kashima, Kashima, Kim, \& Gelfand, 2006; Maass, Karasawa, Politi, \& Suga, 2006). Nonetheless, despite these attributional and linguistic tendencies, more recent work on this topic has revealed that there are many circumstances under which East Asians may be equally, or even more likely, to engage in dispositional thinking. When contextual information was not available or salient, Koreans exhibited the same level of dispositional thinking as Americans did (Choi \& Nisbett, 1998; Choi et al., 1999). Second, although Hong Kong Chinese were less apt than Americans to explain individual behavior in terms of stable personality traits, they did make dispositional attributions when the behavioral unit was a group rather than an individual (Chiu, Morris, Hong, \& Menon, 2000; Menon et al., 1999; Morris, Menon, \& Ames, 2001). Although this research has shown that East Asians readily explain the behaviors of groups in terms of personality traits, it has not addressed the question of whether groups and group members are stereotyped more in East Asian cultures.

Why might groups be seen as possessing distinct personalities in East Asian cultures? As outlined above, cultures differ in the

\footnotetext{
${ }^{1}$ We thank Yoshihisa Kashima for raising this important point.
} 
relative emphasis they place on persons versus groups. In Western psychology, the individual holds the focal point in the layperson's perceptual field and is the primary unit of agentic will and action (Heider, 1958; Masuda \& Nisbett, 2001). As a result, lay people expect a higher degree of coherence in the characteristics and behaviors of a single person than they do in those of a group (Hamilton \& Sherman, 1996). In collectivist societies, however, the group, rather than the individual, is the dominant unit of perception and action. Groups are seen as having stable desires, intentions, and agency - the ability to implement and achieve their goals (Kashima et al., 2004; Menon et al., 1999).

Groups might also be perceived as having enduring dispositions because they have greater permanence and continuity in their memberships in East Asian countries relative to Western ones (Chiu, Dweck, Tong, \& Fu, 1997; Chiu et al., 2000; Su et al., 1999). In all social groups, regardless of culture, individual group members come and go, but new members are continually socialized into the norms of the group. In this way, the characteristic features of the group are maintained over time, allowing for the development of a group-level personality. This may be particularly true in East Asian cultures such as mainland China, where there is less freedom to choose one's group memberships and groups often possess greater stability and coherence among group members. As a consequence, Chinese participants might expect greater internal consistency in the attributes of groups and be more willing than Americans to stereotype at the group level-that is, to ascribe a disposition to an entire collection of individuals.

Why might the "personalities" of groups be transmitted to their members? Groups demand greater conformity and exert greater control over the actions of their members in collectivist societies than in individualist ones. Members of collectivist cultures are expected to suppress their private interests and adjust their personal attributes to fit in with the group (Markus \& Kitayama, 1991; Triandis, 1995). Over time, group members come to take on the attributes of the groups to which they belong; in the parlance of self-categorization theory, they self-stereotype (Turner, Hogg, Oakes, Reicher, \& Wetherell, 1987). The adoption of group-level characteristics does not simply reflect conformity or selfpresentation concerns. Studies using open-ended instruments reveal that East Asians describe themselves more in terms of their group memberships and social roles than do Westerners (Cousins, 1989), indicating that these group identities have been incorporated more closely into the global self-concept.

In sum, knowing about a person's group memberships might be more diagnostic in a collectivist than in an individualist context. As a consequence, Chinese might be more likely to stereotype at the group level-that is, to apply an internally consistent disposition to a collection of individuals - because group members are more likely to actually share group-specific personality traits and to behave in a trait-consistent manner. They may also be more likely to infer personality traits on the basis of a person's group memberships - that is, to stereotype at the individual level.

\section{Culture and Epistemological Entitativity}

If groups are ontologically more entitative in East Asian cultures, it stands to reason that they will also be perceived as more cohesive units. Scholars have become increasingly interested in whether there are cultural differences in perceptions of entitativity (e.g., Brewer, Hong, \& Li, 2004; Kashima et al., 2004). Previous research has shown that Hong Kong Chinese perceive groups as more agentic (Chiu et al., 2000; Menon et al., 1999), and collective agency is considered to be an important aspect of entitativity (Abelson, Dasgupta, Park, \& Banaji, 1998; Brewer et al., 2004). Kashima et al. (2004) showed that whereas participants from five Western countries believed that persons are more agentic than groups, participants from three East Asian countries were equally apt to attribute mental states and agentic will, such as desires and intentions, to group actors as they are to individuals. Although Brewer et al. (2004) reported that Hong Kong Chinese viewed a variety of groups as less entitative than did Americans, most of the limited research on this topic suggests that East Asians see social groups as more cohesive entities. As a consequence, our Chinese participants may perceive both known groups and newly encountered groups as more entitative than will the Americans.

\section{Relationship Between Entitativity and Stereotyping}

People use their lay theories about the nature of social groups to guide social perception and to make dispositional and stereotypic judgments. Certain lay theories about the nature of the social world promote dispositional thinking and stereotyping more than do others. For instance, perceivers who see persons as stable entities are more likely to make trait-based inferences, to endorse stereotypes, and to exhibit intergroup bias (Chiu, Hong, \& Dweck, 1997; Hong et al., 2004; Levy \& Dweck, 1999; Levy, Stroessner, \& Dweck, 1998). In a similar vein, we contend that perceivers who view groups as stable entities possess more internally consistent mental representations of the dispositions of groups. Furthermore, they should make stronger and more consistent inferences about individuals on the basis of their group memberships - that is, they should be more likely to stereotype.

Support for these predictions comes from literature on Western participants showing that the perception of entitativity leads to greater integrative processing (Hamilton \& Sherman, 1996; Susskind, Maurer, Thakkar, Hamilton, \& Sherman, 1999), intergroup categorization (Yzerbyt et al., 1997), dispositional attributions for a group's behavior (Yzerbyt, Rogier, \& Fiske, 1998), and stereotyping (Spencer-Rodgers, Hamilton, \& Sherman, 2007). When forming impressions of highly entitative targets, perceivers make stronger, faster, and more confident trait inferences and recall more target-relevant information, relative to less entitative targets (Susskind et al., 1999). The perception of entitativity also influences the processing of behavioral information about individual group members. Perceiving highly entitative targets involves the abstraction of a distinct group impression or stereotype and the transference of that stereotype across all members of the group (Crawford, Sherman, \& Hamilton, 2002). Other research shows that the perception of entitativity is related to greater stereotyping for both social categories and task groups (Spencer-Rodgers, Hamilton, \& Sherman, 2007).

To summarize, we predicted that Chinese participants, relative to their American counterparts, would perceive a wide range of social groups to be more entitative and, as a result, would make stronger and more internally consistent trait inferences about the groups and their members. Specifically, in Study 1, we predicted that Chinese participants would be more likely than Americans to infer personality traits on the basis of membership in novel, ficti- 
tious social groups. In Study 2, using culturally neutral groups, we predicted that Chinese participants would perceive groups as more entitative and would hold more internally consistent group impressions, compared with Americans. Finally, in Study 3, we tested these hypotheses using existing national groups and examined whether the findings would extend to perceptions of ingroups/ outgroups and their members.

\section{Study 1}

In Study 1, American and Chinese participants made inferences about novel, fictional groups with which neither cultural group could have had an existing relationship. We used fictional groups to focus on the stereotyping process separately from the content. Participants made two types of inferences: First, they made inferences about group membership on the basis of traits provided; that is, they estimated the likelihood that a target individual belonged to one of the groups, given that the individual possessed a personality trait stereotypical of that group. They then made inferences in the opposite direction; that is, the likelihood that an individual possessed a particular personality trait, given that the individual was a member of the group for which that trait was stereotypical. In both cases, we predicted that the Chinese participants would make stronger inferences than would Americans-stronger trait inferences on the basis of social-group membership and stronger group-membership inferences on the basis of traits.

As outlined earlier, cultures differ in their implicit beliefs about the nature of social groups and group membership. We explored participants' beliefs about group membership in the fictional society by asking them to indicate the ease with which they believed that group membership could be changed and the reasons why individuals might belong to one group or another. In keeping with an entitative view of groups, we expected that the Chinese participants would be more likely than Americans to view group membership as stable and as deriving from uncontrollable factors (e.g., inborn traits, social forces, familial choices). In contrast, we expected the American participants to attribute group membership more to individual choice or luck.

\section{Method}

\section{Participants}

University of California, Berkeley (UC Berkeley), students who self-identified as European American $(N=67 ; 61 \%$ female, $39 \%$ male; $M_{\text {age }}=20.9$ years) were selected as the American sample. They participated in the study in exchange for course credit. Peking University (Beijing, China) students $(N=76$; 63\% female, $37 \%$ male; $M_{\text {age }}=21.2$ years) were selected as the Chinese sample. They participated in exchange for 10 yuan (\$1 US).

\section{Procedure}

After participants gave their informed consent, they were asked to complete a questionnaire packet that included questions about "how people group others into categories that are meaningful to them or to society," as well as several measures unrelated to the present study. Upon completion of the questionnaire packet, they were debriefed and thanked, and Chinese participants were paid.

\section{Materials}

Our aim was to develop stimulus materials that would not evoke strong images of any well-known social groups but that nonetheless provided sufficient information to allow participants to make group judgments. Participants read a description of two equalstatus social groups that inhabit a fictional society. ${ }^{2}$ The descriptions were intended to generally imply that the Snoets were an artistic group and the Frints were a scientific group. The description follows.

These two groups, called the Snoets and the Frints, are basically equal in social status and have been known by these terms for many generations. Snoet adults do not necessarily have Snoet offspring, although that sometimes happens. Frints do not necessarily have Frint offspring, although that sometimes happens. Snoets are traditionally known for their fine arts, distinctive regional cuisine, and sturdy dwellings. Frints, by contrast, are traditionally known for their advancements in science and agriculture, as well as their brightly colored garments.

Pilot data revealed that the descriptions indeed suggested an artistic or scientific impression for each group. Pilot participants (18 UC Berkeley students) read the descriptions and generated traits they believed to be characteristic of each group. The most commonly generated traits were creative, adventurous, and sophisticated for Snoets and intelligent, logical, and ambitious for Frints. There was no overlap among the most commonly generated traits for the two groups, suggesting that the impressions formed by pilot participants about each group were distinct. ${ }^{3}$ However, pilot participants did not perceive the stimulus groups to differ in membership desirability, societal respect, or wealth.

After reading the description of the groups, participants made inferences about the likelihood that a hypothetically encountered individual was a member of each group, given that the individual possessed either a stereotypical or nonstereotypical trait. Participants were asked to imagine encounters with individual members of each social group. Specifically, they were asked to "imagine that you meet a member of this society who is extremely [creative], perhaps the most [creative] individual you have met so far." They then rated on a 1 (extremely unlikely) to 7 (extremely likely) scale the likelihood that this individual was a Snoet, the group for which the trait creative was stereotypical, and the likelihood that the individual was a Frint, for which creative was nonstereotypical. These ratings were repeated for all six traits.

Next, participants made inferences about the likelihood that a hypothetically encountered individual would possess a particular

\footnotetext{
${ }^{2}$ In all three studies, the materials were prepared in English and translated into Mandarin Chinese by a bilingual research assistant, then backtranslated into English by a second bilingual research assistant. Resolution of translation discrepancies was made via group consensus with the translators and authors.

${ }^{3}$ Because the pilot testing was conducted only in the United States, it is possible that the stereotypical trait terms generated for each fictional group may have been more salient and meaningful to the American than the Chinese participants. However, this potential cultural bias in the generation of stimuli for the study (stereotypical trait terms) would work against our main hypothesis (that Chinese participants would more readily draw stereotypic inferences, compared with Americans).
} 
trait, given that the individual was a member of the group for which that trait was stereotypical (or nonstereotypical). Specifically, participants were asked to "imagine that you meet a member of this society whom you've been told is a Snoet [Frint]. How [creative] would you expect this individual to be in a social interaction?" Ratings were made on a 1 (extremely unlikely) to 7 (extremely likely) scale for all six traits.

Finally, participants made inferences about the nature of the two social groups. First, they rated on a 1 (not at all difficult) to 5 (extremely difficult) scale how difficult it would be for a Snoet to become a Frint or a Frint to become a Snoet, if the individual wanted to. Second, they rated their agreement on a 1 (strongly disagree) to 7 (strongly agree) scale with five statements that accounted for why individuals might be categorized as Snoets or Frints: "because they are born with certain traits or qualities that affect their outcomes in life," "because of forces in society that they do not have control over," "because of the choices they make as individuals," "because of the choices that their families make or have made in the past," and "because of luck or chance."

\section{Results}

\section{Trait Inferences}

Because our interest was not in the six traits individually, the items involving inferences from traits to group membership were combined into two indices: stereotypical (composed of items regarding creative, adventurous, and sophisticated with respect to the Snoet group and intelligent, logical, and ambitious with respect to the Frint group) and nonstereotypical (composed of items regarding creative, adventurous, and sophisticated with respect to the Frint group and intelligent, logical, and ambitious with respect to the Snoet group). The same was done for the items involving inferences from group membership to traits, resulting in four indices in total. However, reliability analyses on these scales revealed that the trait sophisticated correlated poorly with the other traits, for both stereotypical/nonstereotypical items and for both cultural groups. Thus, this trait was removed from all indices. Cronbach's alphas for the resulting five-item indices are presented in Tables 1 and 2. Several of the alpha coefficients were low, a point to which we return later.

We next performed a 2 (Culture: American vs. Chinese, between-participants) $\times 2$ (Type of Trait: stereotypical vs. nonstereotypical, within-participants) analysis of variance (ANOVA) on the first dependent variable: inferences about traits from group membership. The means and standard deviations are shown in Table 1. As would be expected, there was a significant main effect of type of trait, such that inferences about stereotypical traits were stronger than inferences about nonstereotypical traits, $F(1,142)=$ $125.39, p<.01$. There was also a marginally significant main effect of culture, $F(1,142)=3.44, p=.07$. Overall, Chinese participants made slightly higher likelihood ratings than did the Americans.

It is important to note, however, that these main effects were qualified by a significant Culture $\times$ Type of Trait interaction, $F(1$, $142)=3.77, p<.01$. To explore the interaction, we examined the simple effect of culture separately for the stereotypical and nonstereotypical traits. These analyses revealed that there were cultural differences in inferences about stereotypical traits but not in inferences about nonstereotypical traits. Chinese participants made significantly stronger inferences about stereotypical traits than did Americans, $F(1,142)=11.91, p<.01$, indicating that the Chinese participants stereotyped more than the Americans did. However, the Chinese and American participants did not differ in their inferences about nonstereotypical traits, $F(1,142)<1$, ns.

A second $2 \times 2$ ANOVA was conducted on the second dependent variable-inferences about group membership from traitsand a virtually identical pattern was obtained. Means and standard deviations can be found in Table 2. There was a significant main effect of type of trait, such that participants made stronger group membership inferences on the basis of traits that were stereotypical of the group than on traits that were not stereotypical, $F(1,142)=$ $190.66, p<.01$. In addition, there was a significant main effect of culture, $F(1,142)=15.26, p<.01$. The Chinese participants made stronger inferences than did American participants.

It is important to note, however, that these main effects were qualified by a significant Culture $\times$ Type of Trait interaction, $F(1$, $142)=4.88, p<.05$. Analyses of simple effects revealed cultural differences in inferences of group membership from the stereotypical traits but not from the nonstereotypical ones. Specifically, the Chinese participants made significantly stronger inferences about group membership from stereotypical traits, $F(1,142)=19.01$, $p<.01$, compared with the American participants. However, no cultural difference was seen in inferences about group membership from nonstereotypical traits, $F(1,142)<1$, ns.

Finally, because the alphas for these indices were somewhat low (see Tables 1 and 2), we also examined the directional patterns for the five stereotypical traits individually. The Chinese participants made significantly stronger group-membership-to-stereotypicaltraits inferences than the Americans did for four of five traits, $p \mathrm{~s}<$ .05 , and marginally stronger inferences for the fifth trait, $p<.10$. Chinese participants made significantly stronger stereotypicaltraits-to-group-membership inferences than the Americans did for

Table 1

Inferences About Traits on the Basis of Group Membership, Study 1

\begin{tabular}{lcccccccc}
\hline & \multicolumn{3}{c}{ American participants } & & \multicolumn{3}{c}{ Chinese participants } \\
\cline { 2 - 3 } Type of traits & $\begin{array}{c}\text { Likelihood } \\
\text { rating }\end{array}$ & $S D$ & $\begin{array}{c}\text { Index } \\
\text { reliability }\end{array}$ & & $\begin{array}{c}\text { Likelihood } \\
\text { rating }\end{array}$ & $S D$ & $\begin{array}{c}\text { Index } \\
\text { reliability }\end{array}$ \\
\hline Stereotypical & 3.60 & 0.59 & .70 & & 3.96 & 0.66 & .64 \\
Nonstereotypical & 3.03 & 0.60 & .70 & & 2.93 & 0.56 & .44 \\
\hline
\end{tabular}

Note. Likelihood ratings were made on a 1-7 scale. Reliability scores were calculated with Cronbach's alpha. 
Table 2

Inferences About Group Membership on the Basis of Traits, Study 1

\begin{tabular}{lcccccccc}
\hline & \multicolumn{3}{c}{ American participants } & & \multicolumn{3}{c}{ Chinese participants } \\
\cline { 2 - 3 } Type of traits & $\begin{array}{c}M \text { Likelihood } \\
\text { rating }\end{array}$ & $S D$ & $\begin{array}{c}\text { Index } \\
\text { reliability }\end{array}$ & & $\begin{array}{c}M \text { Likelihood } \\
\text { rating }\end{array}$ & $S D$ & $\begin{array}{c}\text { Index } \\
\text { reliability }\end{array}$ \\
\hline Stereotypical & 5.03 & 0.81 & .66 & & 5.60 & 0.76 & .32 \\
Nonstereotypical & 3.84 & 0.71 & .48 & & 3.96 & 0.93 & .46 \\
\hline
\end{tabular}

Note. Likelihood ratings were made on a 1-7 scale. Reliability scores were calculated with Cronbach's alpha.

three of the five traits, $p \mathrm{~s}<.05$, and for the remaining two traits, the means were in the predicted direction. Thus, the pattern of cultural differences was also shown at the level of the individual items.

\section{Inferences About the Nature of the Groups}

When asked about the ease with which individuals in the fictional society could move from one group to another, Chinese participants reported that they thought this would be a significantly more difficult task than American participants did. Chinese participants $(M=3.45, S D=0.99)$ thought it would be more difficult than did the Americans $(M=2.72, S D=1.08)$ for a Snoet to become a Frint, if the individual wanted to, $F(1,142)=17.84, p<$ .01 . The Chinese participants $(M=3.07, S D=1.14)$ also believed that it would be more difficult than did the American participants $(M=2.64, S D=1.05)$ for a Frint to become a Snoet, $F(1,142)=$ $5.31, p<.05$.

Participants from the two cultural groups also showed some differences in the inferences they made about group membership in the fictional society. Americans $(M=4.93, S D=1.52)$ were significantly more likely than the Chinese participants $(M=4.09$, $S D=2.06)$ to attribute social-group membership to individual choice, $F(1,142)=7.40, p<.01$, and more likely $(M=3.19$, $S D=1.67)$ than the Chinese $(M=2.36, S D=1.44)$ to attribute membership to luck or chance, $F(1,142)=10.39, p<.01$. In contrast, the Chinese participants $(M=4.39, S D=1.84)$ were marginally more likely than the Americans $(M=3.87, S D=1.69)$ to attribute group membership to inborn traits, $F(1,136)=2.96$, $p=.09$. There was no difference in attributions to social forces, $F<1$, or to familial choices, $F(1,142)=1.07$, $n s$, as a function of culture.

\section{Discussion}

In this study, Chinese and American participants made different inferences about a hypothetical target individual on the basis of the target's membership in a novel social group. We reasoned that if Chinese tend to hold a more entitative view of groups than do Americans, they should be more inclined to make stereotypic judgments on the basis of group membership. Consistent with our predictions, Chinese participants thought it was more likely than did American participants that the target individual belonged to a particular group, given that the individual possessed a personality trait stereotypical of that group. Similarly, the Chinese participants thought it was more likely than did Americans that the target individual possessed a stereotypical personality trait, given that the individual was known to be a member of a group for which the trait was stereotypical. The fact that members of the two cultures did not differ in their inferences about nonstereotypical traits indicates that these results cannot be explained by an acquiescence bias (Smith, 2004) or a general tendency to endow group members with dispositional qualities among the Chinese participants. Rather, their relatively stronger trait inferences are limited to traits believed to be stereotypic of the group.

Consistent with an entitative view of groups, the Chinese participants also viewed social-group membership as more permanent, as marginally more trait-based, and as less attributable to individual choice than did the American participants. These findings are consistent with a culturally shared implicit belief that social aggregates possess entitative, consistent personalities that are transmitted to individual members. As a whole, these results provide preliminary support for our hypothesis that the Chinese participants would perceive social-group membership to be more diagnostic of personality than would the Americans. We tested this hypothesis further in two additional studies that directly assessed beliefs about group entitativity.

\section{Study 2}

The central purpose of Study 2 was to test whether Chinese view groups as more entitative and as possessing more internally consistent dispositions or personalities than do Americans. For this study, we selected a fictional group (a small work group) and an existing national group (Kenyans). These target groups were thought to be culturally neutral in that both Chinese and Americans should have few prior expectations about the groups.

In Studies 2 and 3, we employed an idiographic measure of dispositional inference, or group-level stereotyping. Stereotypes have been conceptualized and measured as both idiographic belief systems and as culturally shared or consensual perceptions of groups and their members. Individual beliefs about a social group can differ significantly from one's familiarity with or proclivity to endorse a consensual stereotype (Devine, 1989). We elected to use an idiographic approach with the existing national groups in Studies 2 and 3, because these measures are generally less susceptible to social-desirability concerns than are traditional stereotype-rating scales (Stangor \& Lange, 1994).

Specifically, we assessed the degree to which the target groups as a whole were seen as possessing personality traits that are internally (not temporally) consistent. Participants rated each target group on pairs of contrasting traits, such as organized and disorganized. Because we were interested in the consistency of 
dispositional inferences, rather than their content, the adjectives were not selected to be consensual, stereotypic attributes of the groups. Rather, we included a broad array of attributes representing various aspects of personality, and we used consistency scores to measure the extent to which the participants held consistent group impressions. ${ }^{4}$ For example, if a participant rated a target group as very high on organized, then an internally consistent response would be to rate the group as very low on the opposite trait, disorganized. We predicted that Chinese participants would be more likely than Americans to ascribe an internally consistent set of personality traits to the groups as a whole. We further predicted that perceptions of group entitativity would mediate the observed cultural differences in group-personality consistency.

\section{Method}

\section{Participants}

Students at UC Berkeley ( $N=64,52 \%$ female, $48 \%$ male, $M_{\text {age }}=20.6$ years) who self-identified as European American were selected as the American sample. They participated for partial course credit. Students at Peking University $(N=80,60 \%$ female, $40 \%$ male, $M_{\text {age }}=21.4$ years) were selected as the Chinese sample. They were paid 10 yuan (\$1 US) for their participation.

\section{Procedure}

The participants were invited to take part in a study on "how people are perceived." After granting their informed consent, they completed a questionnaire packet that included a number of dependent measures, including attribute ratings, group entitativity, and attitudes toward the groups, and several measures unrelated to the present study. Upon completion of the questionnaire, they were debriefed and thanked, and Chinese participants were paid.

\section{Materials}

Participants were presented with two target groups, and they rated each group on the same dependent measures. The two groups were included as replications to examine generality of findings.

For the work-group target, participants were told they would read about a group of employees who, for reasons of confidentiality, were identified only by their initials. They were instructed to think about the group as whole, rather than a specific member of the group, and to respond on the basis of their general, overall impression of the group. They read a page-long description of the group that included the following:

The work group is made up of seven people. [They] create software programs for a large computer company. ... Each group member has a clearly defined role and function within the group. In general, the group members get along very well, and they are very happy to be members of this work group.... On weekends, C. C. likes to go to the movies. After going out, C. C. enjoys eating late-night meals with his friends at their favorite restaurant... . K. H. enjoys taking peaceful walks in the mountains alone, reading novels, and watching television in his free time... .

Similar capsule descriptions were included about all seven group members.
For the national-group target, participants rated the group Kenyans. The instructions included the following: "Below you will find a list of traits that may be used to describe Kenyans. By the term Kenyans, we mean citizens of Kenya in Africa. Think about Kenyans as a national group...." The order in which the targets and dependent measures were presented was counterbalanced across all participants.

\section{Measures}

Entitativity. Perceptions of group entitativity were based on 14 items shown in the Appendix. Various researchers have conceptualized and defined group entitativity in different ways (e.g., Brewer et al., 2004; Hamilton, Sherman, \& Spencer-Rodgers, 2004; Hamilton et al., 1998; Kashima et al., 2004; Rothbart \& Park, 2004; Yzerbyt, Corneille, \& Estrada, 2001). For the present study, we developed a global measure of group entitativity that assesses various aspects of the construct as it is represented in the literature. These 14 items were averaged to create a single entitativity index. ${ }^{5}$ Cronbach's alphas for the work group were .84 for Chinese and .69 for Americans; and for Kenyans, $\alpha=.79$ for Chinese and $\alpha=.87$ for Americans.

Attribute ratings. Participants rated the groups on 14 pairs of contrasting attributes, with each attribute in the pair rated separately. We generated a broad array of attributes tapping different aspects of personality (organized/disorganized, self-sacrificing/ self-centered, quiet/talkative, submissiveldominant, realistic/ idealistic, modern/traditional, emotional/logical, undependablel loyal, intelligent/foolish, humblelproud, determined/carefree, shy/ sociable, inventive/unimaginative, rebellious/obedient). Altogether, the groups were rated on 28 unipolar scales, which ranged from 1 (not at all characteristic) to 9 (very characteristic).

Consistency values. To assess the consistency of participants' group-personality judgments on the contrasting pairs of attributes,

\footnotetext{
${ }^{4}$ Some researchers refer to these scores as ambivalence or inconsistency scores. Because we are interested in the internal consistency of participants' group impressions, we reversed the ambivalence scores and refer to them in this article as consistency scores.

${ }^{5}$ For cross-cultural comparisons, it is important to document that this measure has comparable structure and that the items have similar factor loadings in the two cultures. Toward this end, we conducted exploratory factor analyses and examined one-, two-, and three-factor solutions separately for each target group in each culture. The two- and three-factor solutions did not cohere theoretically and were not consistent across targets and cultures. The one-factor solution corresponded more closely to our theoretical conceptualization of global entitativity and was quite consistent for Chinese and American participants. Hence, a one-factor model was determined to be the most appropriate for investigating between-culture effects. Further, to examine the cross-cultural equivalence of the individual items, we tested whether the magnitude of the factor loadings differed significantly for Chinese and American participants (see Byrne, 2001). Specifically, we examined a one-factor model using structural equationmodeling techniques in AMOS 5.0. The factor loadings were constrained to be equal across the cultural groups, and the model fits were compared via multigroup analysis. For the target group Kenyans, factor loadings for 13 of the 14 items were cross-culturally equivalent, as indicated by nonsignificant chi-square difference tests (all $p \mathrm{~s}>.05$ ). For the work group, factor loadings for 8 of the 14 items were equivalent.
} 
Table 3

Entitativity Ratings and Consistency Values by Participant Culture and Group Target, Study 2

\begin{tabular}{|c|c|c|c|c|c|c|c|c|}
\hline \multirow[b]{3}{*}{ Participant culture } & \multicolumn{4}{|c|}{ Entitativity rating } & \multicolumn{4}{|c|}{ Consistency value } \\
\hline & \multicolumn{2}{|c|}{ Work group } & \multicolumn{2}{|c|}{ Kenyans } & \multicolumn{2}{|c|}{ Work group } & \multicolumn{2}{|c|}{ Kenyans } \\
\hline & $M$ & $S D$ & $M$ & $S D$ & $M$ & $S D$ & $M$ & $S D$ \\
\hline Chinese & 5.77 & 1.00 & 6.35 & 0.83 & 0.28 & 0.08 & 0.27 & 0.09 \\
\hline American & 5.43 & 0.68 & 5.63 & 0.99 & 0.25 & 0.10 & 0.22 & 0.09 \\
\hline
\end{tabular}

Note. Entitativity ratings were made on a 1-9 scale.

we used the negative acceleration model (NAM; Scott, 1966). ${ }^{6}$ As described above, people's beliefs were assessed with separate, unidimensional scales, which allowed for two independent judgments. We then applied a formula (described below) to each of the pairs of attribute ratings to obtain a single, numerical index of the extent to which the participants' group impressions were internally consistent. We then averaged these consistency values to obtain a mean consistency score for each participant.

We computed the NAM scores using the formula $[(2 \times \mathrm{S})+$ $1] /(S+L+2)$, where $L$ is the larger value (dominant response) and $\mathrm{S}$ is the smaller value (conflicting response). This scale ranged from .25 to .95 , with a higher score indicating a more ambivalent or inconsistent response. For ease of interpretation, we then reversed the scale such that a larger value indicates a more consistent response. (The scale was reversed by subtracting all the values from the highest possible score of .95). Hence, the new reversed scores ranged from 0 to .70. For instance, if a participant rated the work group as 9 on organized and 1 on disorganized, then organized is the dominant response $(\mathrm{L}=9)$, disorganized is the conflicting response $(S=1)$, and NAM $=.25$. After reverse scoring, NAM $=.95-.25=.70$. Thus, a consistency score of .70 reflects a highly internally consistent set of responses. Consider another example: Rating a group as 9 on organized and 9 on disorganized would yield a consistency score of 0 (NAM $=.95-$ $.95=0$ ) and reflects a highly inconsistent (or highly ambivalent) response. $^{7}$

Group evaluations. Participants answered the question "Overall, how positive or negative is your impression of [target group]?" using a -4 (very negative) to +4 (very positive) scale.

Follow-up questions. For the ratings of Kenyans only, participants were asked the following: (a) "How familiar are you with the group?" ( 1 = not at all familiar, 9 = very familiar $)$, (b) "How important is the group to you personally?" $(1=$ not at all important, 9 = very important), and (c) "How much social contact have you had with members of the group?" $(1=$ no contact, $9=$ a great deal of contact).

\section{Results}

\section{Entitativity}

A 2 (Culture: American vs. Chinese, between-participants) $\times 2$ (Target Group: work group vs. Kenyans, within-participants) ANOVA was conducted on the entitativity index. The mean values and standard deviations are shown in the left half of Table 3. As predicted, there was a highly significant main effect of culture. Chinese participants $(M=6.06, S E=0.075)$ rated the target groups as significantly more entitative than did Americans $(M=$ 5.53, $S E=0.084), F(1,142)=22.21, p<.001$. In addition, participants rated the national group Kenyans $(M=5.99, S E=$ $0.076)$ as more entitative than the fictional work group $(M=5.60$, $S E=0.073), F(1,142)=15.99, p<.001 .^{8}$ Last, there was a marginally significant Culture $\times$ Target Groups interaction, $F(1$, $142)=3.77, p=.054$. This interaction was due to the fact that the cultural difference in entitativity ratings was greater for Kenyans, $t(142)=4.74, p<.001$, than for the work group, $t(142)=2.34$, $p<.05$.

\section{Group-Personality Consistency}

Preliminary analyses indicated that the 14 pairs of attributes were approximately matched in terms of valence in each culture. At the end of the study, a subgroup of participants (33 Chinese, 26 Americans) rated the valence of the 28 attributes on a -4 (very negative) to +4 (very positive) scale. We then computed the absolute difference in valence ratings for each of the contrasting attribute pairs (e.g., valence of organized minus valence of disorganized) and computed the mean across the 14 attribute pairs.

\footnotetext{
${ }^{6}$ A number of different formulas have been developed to index consistency in participants' responses. To provide convergent evidence for our hypotheses, we also computed the consistency values using the SimilarityIntensity Model (Thompson, Zanna, \& Griffin, 1995), computed as (3S L) and reverse scored. We obtained comparable results.

${ }^{7}$ Because internal consistency is reflected in both the extremity and similarity of a participant's responses (Priester \& Petty, 1996; Thompson et al., 1995), consistency scores are generally superior to other consistency indicators, such as simple difference scores or correlations. Consider the following: If a target is rated as 3 (a little) on shy and 3 (a little) on outgoing, the target would obtain a difference score of 0 . If the target is rated as 7 (very much) on shy and 7 (very much) on outgoing, the target would obtain the same score of 0 , even though the latter responses are less internally consistent. (Possessing a large amount of two opposing traits is less coherent than possessing a small amount of two opposing traits.) The consistency scores, on the other hand, take into account both the similarity of the responses (i.e., how close together the ratings are) and the intensity of the responses (i.e., how extreme the ratings are) and, therefore, are more sensitive indicators over a broad range of responses. We also computed difference scores on the basis of | $\mathrm{L}-\mathrm{S} \mid$ and obtained comparable results.

${ }^{8}$ One might expect the small work group to be rated as more entitative than the large national group. On the other hand, participants were provided with a great deal of information about the individual members of the work group and their unique personality attributes. This might have led to the perception of the work group as less unified and cohesive.
} 
There were no differences in the mean valence ratings $\left(M_{\text {China }}=\right.$ $\left.3.49, S D=0.94 ; M_{\mathrm{US}}=3.25, S D=0.81\right), F(1,57)=1.10$, $n s$.

A second $2 \times 2$ ANOVA was conducted on the consistency scores. The means and standard deviations are presented in the right half of Table 3. Both main effects were significant. As predicted, the Chinese participants $(M=0.28, S E=0.009)$ held more internally consistent impressions of the target groups than did the Americans $(M=0.24, S E=0.010), F(1,142)=11.29$, $p<.001$. In addition, participants held more consistent impressions of the work group $(M=0.27, S E=0.008)$ than the national group $(M=0.24, S E=0.008), F(1,142)=8.78, p<.01$. There was no Culture $\times$ Target Group interaction, $F(1,142)=1.6$, ns. Chinese participants rated both target groups as having a more internally consistent personality than did the Americans.

\section{Group Evaluations}

To ensure that the cultural differences in the consistency ratings were not merely due to differences in group evaluations, we asked participants to rate their overall evaluation of each group. A $2 \times$ 2 ANOVA revealed no cultural differences in evaluative orientation toward the groups, $F(1,142)<1$. Chinese and American participants did not differ in their attitudes toward the work group $\left(M_{\text {China }}=1.44, S D=1.47 ; M_{\mathrm{US}}=1.35, S D=1.25\right), t(142)<1$, or Kenyans $\left(M_{\text {China }}=0.63, S D=1.72 ; M_{\mathrm{US}}=0.93, S D=1.47\right)$, $t(142)=1.14, n s$. There was a main effect of target group, such that overall, the work group $(M=1.40, S E=0.116)$ was rated more favorably than were Kenyans $(M=0.78, S E=0.135), F(1$, $142)=14.97, p<.001$. However, there was no Culture $\times$ Target Group interaction, $F(1,142)=1.57, n s$.

In addition, we repeated the consistency analyses (described above) using the attitude measures as covariates. Notably, the main effect of culture remained significant, $F(1,140)=10.66, p<$ .001 . Hence the Chinese participants did not perceive the groups as having more internally consistent personalities, relative to the Americans, simply because they hold more positive (or negative) attitudes toward the groups.

\section{Follow-up Questions}

Chinese participants $(M=3.70, S D=2.38)$ said they were more familiar with the national group Kenyans than Americans did $(M=2.36, S D=1.64), F(1,142)=14.65, p<.001$. They also indicated that the group was more important to them personally $\left(M_{\text {China }}=4.84, S D=2.70 ; M_{\mathrm{US}}=3.27, S D=1.73\right), F(1,142)=$ $16.29, p<.001$, and they tended to have greater social contact with the group $\left(M_{\mathrm{China}}=2.58, S D=2.43 ; M_{\mathrm{US}}=2.02, S D=\right.$ $1.45), F(1,142)=2.71, p=.10$. We conducted an analysis of covariance on the consistency scores for Kenyans, using culture as the factor and the three variables (familiarity, importance, and social contact) as covariates. It is notable that the effect of culture remained significant and indeed became stronger after we controlled for these variables, $F(1,139)=14.32 p<.001$. Thus, the Chinese participants did not perceive the national group as having a more internally consistent personality simply because the target group is more familiar or important to them.

\section{Relationship Between Entitativity and Group-Personality Consistency}

We predicted that groups that are perceived as tightly knit entities would also be ascribed more consistent group personalities. As we hypothesized, perceptions of entitativity were positively related to personality consistency for both of the target groups, and this association generally held for both Chinese and American participants. For the work group, the correlation was $r=$ $.41, p<.001$, in the total sample, and the correlations were substantial for both Chinese participants, $r=.50, p<.001$, and American participants, $r=.32, p<.05$. Likewise, for Kenyans, perceptions of entitativity were positively related to grouppersonality consistency in the total sample, $r=.30, p<.001$. The association was marginally significant for Chinese participants, $r=.19, p=.10$, and significant for American participants, $r=$ $.26, p<.05$.

Next, we conducted mediational analyses to test whether entitativity mediates the relationship between culture and grouppersonality consistency. First, for the work group, the consistency scores were regressed on culture $(\beta=.17, p<.05)$. Next, the mediator (perceptions of entitativity) was regressed on culture $(\beta=.37, p<.001)$. Last, personality consistency was regressed on culture and entitativity simultaneously, and the association between culture and personality consistency was no longer significant $(\beta=.10, n s$; Sobel test, $\Delta \beta=.07, p=.10)$. For Kenyans, the consistency scores were regressed on culture $(\beta=.29, p<$ $.001)$, and the mediator (entitativity) was regressed on culture $(\beta=$ $.37, p<.001)$. Last, personality consistency was regressed on culture and entitativity simultaneously, and there was a significant drop in the association between culture and personality consistency $(\beta=.20, p<.05$; Sobel test, $\Delta \beta=.09, p<.05)$. These findings document that perceptions of entitativity account at least in part for the link between culture and group-personality consistency.

\section{Discussion}

As we hypothesized, Chinese participants perceived both target groups as more entitative and as having a more consistent group personality than did Americans. This was true for both a small work group and a large, existing social category (Kenyans). Thus, our findings appear to generalize across two different types of groups. Moreover, we found that perceptions of group entitativity explained a significant or marginally significant proportion of the cultural variation in group-personality consistency. We were also able to rule out several alternative explanations for our findings, including cultural differences in evaluations of the groups; the valence of the traits that were rated; and, for the national group, the degree of importance, familiarity, or prior social contact with the group.

It is important to note that although the Chinese held more consistent impressions of the groups' personalities than did the Americans, they did not hold more prejudicial attitudes toward the groups, as suggested by their equivalent scores on the evaluation items. Several decades worth of research using Western samples indicates a moderate but fairly reliable association between stereotyping and prejudice (Fiske, 1998). People are motivated to differentiate ingroups from outgroups and to favor their ingroups, 
with the aim of enhancing their self-esteem. Among Chinese, however, stereotyping and dispositional inference might stem more from factors other than self-esteem enhancement, such as a collectivist orientation, epistemic beliefs about the nature of groups (Y. Chen, Brockner, \& Chen, 2002), and perceptions of group entitativity. Thus, Chinese participants might make more stereotypical and dispositional inferences about social groups than do Americans without necessarily holding more prejudiced attitudes toward the groups or their members.

In the next study, we sought to replicate and extend our findings to existing national groups that would be highly salient and important to the participants-groups about which participants would be more likely to hold definite dispositional beliefs. Specifically, participants rated an ingroup and an outgroup. A second purpose of the study was to test whether cultural differences in perceived personality consistency would extend to perceptions of a specific member of the group.

\section{Study 3}

In Study 3, Chinese and American participants were asked to judge the groups Chinese and Americans. Thus, members of each cultural group rated their own national group (the ingroup) and the other national group (the outgroup). We predicted that Chinese participants, given their tendency to see groups as natural units of analysis, would perceive both national groups as more entitative and as having more internally consistent personalities, relative to Americans. We also expected that these effects might be qualified by the ingroup/outgroup status of the perceiver, as described below. Last, we hypothesized that higher entitativity judgments would be associated with the perception of a more consistent group personality. That is, participants who viewed the target groups as tightly knit entities would also be more likely to ascribe an internally consistent set of personality traits to the groups.

The literature on how ingroup/outgroup membership influences perceptions of group entitativity is decidedly mixed. Abelson et al. (1998) argued that outgroups are perceived as higher in entitativity than ingroups because the former are seen as more agentic and threatening. On the other hand, Crump, Hamilton, Sherman, and Thakker (2005) found that ingroups are often rated as more entitative than outgroups. Ingroups have high social-identity value (Sherman, Hamilton, \& Lewis, 1999). They are important and meaningful to their members, and people are frequently motivated to perceive them as unified and cohesive (Castano, Yzerbyt, \& Bourguignon, 2003; Yzerbyt, Castano, Leyens, \& Paladino, 2000). Thus, there is evidence for both outgroup-entitativity and ingroupentitativity effects. All of these studies used Western samples; to our knowledge, these questions have not been examined in East Asian cultures.

Paralleling our predictions for group entitativity, described earlier, we hypothesized that Chinese participants would perceive the target groups as possessing more internally consistent personalities than would Americans, although again, we expected that these effects might be moderated by the ingroup/outgroup status of the perceiver. Outgroups are generally perceived as more homogenous than are ingroups, although ingroup homogeneity effects are observed under certain conditions (e.g., Simon, 1992). Indeed, the outgroup homogeneity effect is one of the most robust in social psychology (Fiske, 1998). The tendency to see outgroups as highly similar is also prevalent in East Asian cultures (Kashima, 2001), although some cross-cultural work shows that East Asians may rate ingroups as more homogenous than outgroups, because they are collectivistic and strongly motivated to view their ingroups as unified and cohesive (Y. Lee \& Ottati, 1993, 1995; Triandis, McCusker, \& Hui, 1990).

In sum, the literature suggests potentially competing hypotheses regarding the relationships among culture, group entitativity, group-personality consistency, and ingroup/outgroup membership. Outgroups may be seen as more entitative and homogenous than ingroups (Abelson et al., 1998; Fiske, 1998), or ingroups may be seen as more entitative and homogenous than outgroups (Crump et al. 2005; Simon, 1992), especially among Chinese participants (Y Lee \& Ottati, 1995; Triandis et al., 1990). We tested these competing hypotheses in the present study, in conjunction with our primary focus on the role of culture in group perception.

Participants also made ratings about an individual who represented each group, John (an "American college student") and Lee (a "Chinese college student"). On the one hand, one might expect members of an individualistic culture (Americans) to rate individual targets as possessing greater personality consistency than would members of a collectivistic culture (Chinese), in keeping with the expectation of a cohesive, stable self in Western cultures and a dialectical, flexible self in Eastern cultures (Hamilton \& Sherman, 1996; Spencer-Rodgers, Boucher, Mori, Wang, \& Peng, 2007). In the present context, however, the targets were identified as group members, rather than simply as separate, unique individuals. Moreover, the descriptions of the two target individuals were identical with the only exception that they differed in their group memberships, thereby further highlighting their status as group members. Therefore, we expected that the individual judgments would be based on group impressions, and we predicted that Chinese participants would rate John (translated as Yuehan in Chinese) and Lee (Xiaoming in Chinese) as having more internally consistent personalities than would Americans.

\section{Method}

\section{Participants}

Students at UC Berkeley ( $N=52,65 \%$ female, $35 \%$ male, $M_{\text {age }}=20.4$ years) who self-identified as European American were selected as the American sample. They participated for partial course credit. Students at Peking University $(N=62,50 \%$ female, $50 \%$ male, $M_{\text {age }}=20.6$ years) were selected as the Chinese sample. They were paid 10 yuan (\$1 US).

\section{Procedure}

The procedures were generally the same as in Study 2. Participants completed a questionnaire packet that included the same dependent measures as those used in Study 2. The order in which the targets and dependent measures were presented was counterbalanced across all participants.

\section{Materials and Measures}

Participants rated two groups, Americans and Chinese, and 2 individuals, John (Yuehan) and Lee (Xiaoming). Thus, all four targets (Americans, Chinese, John, and Lee) were rated on the 
Table 4

Entitativity Ratings and Consistency Values by Participant Culture and Group Target, Study 3

\begin{tabular}{|c|c|c|c|c|c|c|c|c|}
\hline \multirow[b]{4}{*}{ Participant culture } & \multicolumn{8}{|c|}{ Group Target } \\
\hline & \multicolumn{4}{|c|}{ Entitativity rating } & \multicolumn{4}{|c|}{ Consistency value } \\
\hline & \multicolumn{2}{|c|}{ Americans } & \multicolumn{2}{|c|}{ Chinese } & \multicolumn{2}{|c|}{ Americans } & \multicolumn{2}{|c|}{ Chinese } \\
\hline & $M$ & $S D$ & $M$ & $S D$ & $M$ & $S D$ & $M$ & $S D$ \\
\hline Chinese & 5.71 & 0.82 & 6.19 & 0.84 & 0.37 & 0.09 & 0.29 & 0.07 \\
\hline American & 4.94 & 0.96 & 6.47 & 0.78 & 0.28 & 0.08 & 0.29 & 0.09 \\
\hline
\end{tabular}

Note. Entitativity ratings were made on a 1-9 scale.

same 14 pairs of contrasting traits, measure of entitativity, and group-evaluation items as in Study 2.

For the national groups, the instructions included the following: "Below you will find a list of traits that may be used to describe Americans. By the term Americans, we mean citizens of the United States. Think about Americans as a national group. ..." For the group members, participants read a page-long description that included the following:

[John] is an [American] college student at a medium-sized university in [the United States]. He is in his second year of college, and he is studying literature. [John] is a good student, but he feels that he could devote more time to studying. ... [John] often plays practical jokes on his classmates, which has earned him a reputation for his humorous nature. ...

The instructions were the same for Chinese targets, except that the terms Lee, Chinese, and China were used instead.

We computed consistency scores for each of the four targets using the same procedures as those outlined for Study 2. For the entitativity measure, Cronbach's alphas for the target group Chinese were .74 for Chinese participants and .77 for American participants; for the target group Americans, they were .70 for Chinese participants and .80 for American participants. ${ }^{9}$

\section{Results}

\section{Perceptions of Group Targets}

Design. In the following ANOVAs, we employed a full ingroup-outgroup design (see Judd \& Bartsch, 1995; Park \& Rothbart, 1982), in which raters from two participant groups judged both their own group (ingroup) and the other group (outgroup). Thus, participant group and target group are crossed factors in the design, and an ingroup/outgroup effect, if present, emerges as a Participant Group $\times$ Target Group interaction. A major strength of this design is that participant-group effects (i.e., differences in perceptions between Chinese and American participants), target-group effects (i.e., differences in perceptions of the target groups), and ingroup/outgroup effects can be examined separately.

Entitativity. A 2 (Culture: Chinese vs. American, betweenparticipants) $\times 2$ (Target Group: Chinese vs. Americans, withinparticipants) ANOVA was conducted on the entitativity index. Mean values and standard deviations are shown in the left half of Table 4. As we predicted, there was a significant main effect of culture, $F(1,112)=4.98, p<.05$. On average, Chinese participants rated the target groups as more entitative $(M=5.95, S E=$ $0.075)$ than did Americans $(M=5.70, S E=0.082)$. There also was a significant main effect of target group, $F(1,112)=76.74$, $p<.001$, such that the group Chinese $(M=6.33, S E=0.076)$ was rated as more entitative than the group Americans $(M=5.32$, $S E=0.083)$. Finally, there was a significant Culture $\times$ Target Group interaction, $F(1,112)=21.13, p<.001$.

To decompose the interaction, we held the target group constant while comparing ingroup and outgroup judgments (see Judd \& Bartsch, 1995; Park \& Rothbart, 1982). First, we focused on the stimulus group Americans and compared the ratings made by the outgroup (Chinese participants) with the ratings made by the ingroup (American participants). Next, we focused on the stimulus group Chinese and compared the ratings made by the outgroup (American participants) with those made by the ingroup (Chinese participants).

These analyses revealed that outgroups tended to be perceived as more entitative than ingroups. Chinese participants rated Americans as significantly more entitative than did American participants, $t(112)=4.66, p<.001$, and American participants tended to rate Chinese as more entitative than did Chinese participants, $t(112)=1.83, p=.07$. In sum, members of both cultural groups (especially Chinese participants) tended to exhibit outgroup entitativity effects.

Group-personality consistency. A second $2 \times 2$ ANOVA was conducted on the consistency scores. The mean values and standard deviations are shown in the right half of Table 4. There was a significant main effect of culture, $F(1,112)=8.35, p<.01$. As we predicted, Chinese participants perceived the national groups as having more internally consistent personalities $(M=0.33, S E=$ $0.009)$ than did American participants $(M=0.29, S E=0.010)$. In addition, there was a main effect of target group, $F(1,112)=$ 20.90, $p<.001$, such that, overall, the group Americans was

\footnotetext{
${ }^{9}$ Factor analyses for Study 3 were conducted in the same manner as those for Study 2 (see Footnote 5). Again, a one-factor model, but not a two- or a three-factor model, was quite consistent across cultures for both of the target groups. For the group Americans, factor loadings for 11 of the 14 items were cross-culturally equivalent; chi-square difference tests were all nonsignificant ( $p \mathrm{~s}>.05$ ). For the group Chinese, factor loadings for all 14 items were cross-culturally equivalent. Hence, the factor structure and loadings of the entitativity measure were highly similar for Chinese and American participants.
} 
perceived as having a more consistent personality $(M=0.32$, $S E=0.008)$ than the group Chinese $(M=0.29, S E=0.009)$. Finally, there was a significant Culture $\times$ Target Group interaction, $F(1,112)=40.07, p<.001$. This interaction reflects higher consistency ratings of Americans made by Chinese participants than by American participants, $t(112)=5.50, p<.001$, whereas no cultural difference was evident for the ratings of Chinese, $t(112)<1$. Another way of interpreting these data is that, for Chinese participants only, there was an outgroup consistency effect.

Group evaluations. A $2 \times 2$ ANOVA was conducted on the group-evaluation measures. There was no main effect of culture, $F(1,112)<1$. On average, Chinese participants $(M=0.97, S E=$ $0.15)$ and American participants $(M=1.04, S E=0.16)$ did not differ in their attitudes toward the target groups. There was no main effect of target group, $F(1,112)<1$. There was, however, a marginally significant Culture $\times$ Target Group interaction, $F(1$, $112)=3.40, p=.07$.

American participants rated their ingroup, Americans $(M=$ $1.19, S D=1.71)$, somewhat more favorably than did Chinese participants $(M=0.76, S D=1.55)$, although this difference was not significant $t(112)=1.39$, ns. Similarly, Chinese participants rated their ingroup, Chinese $(M=1.19, S D=1.49)$, somewhat more favorably than did American participants $(M=0.90, S D=$ $1.45)$, but again, this difference was not significant, $t(112)=1.03$, $n s$. Thus, both Chinese and Americans exhibited some (nonsignificant) ingroup favoritism, to a comparable degree.

In addition, we repeated the consistency analyses (described above) using the group-evaluation measures as covariates. It is important to note that the main effect of culture remained significant, $F(1,110)=9.05, p<.001$. Hence, Chinese participants did not perceive the national groups as having more internally consistent personalities simply because they held more positive (or negative) attitudes toward the groups.

\section{Perceptions of Group Members}

We predicted that the Chinese participants would make more consistent dispositional inferences with respect to the group members, John and Lee, than would the American participants. We conducted a 2 (Culture: Chinese vs. American, betweenparticipants) $\times 2$ (Target: John vs. Lee, within-participants) ANOVA on the consistency indices. As we hypothesized, there was a significant main effect of culture, $F(1,112)=18.60, p<$ .001. Paralleling the results at the level of the national groups, Chinese participants $(M=0.31, S E=0.010)$ perceived the group members as having more internally consistent personalities than did American participants $(M=0.25, S E=0.011)$. In addition, there was a significant main effect of target, $F(1,112)=15.38$, $p<.001$, such that John $(M=0.29, S E=0.008)$ was rated as having a more consistent personality than was Lee $(M=0.27$, $S E=0.008)$. Last, there was a Culture $\times$ Target interaction, $F(1$, $112)=3.94, p=.05$. This interaction reflects the fact that the culture effect was greater when participants judged John $\left(M_{\text {China }}=\right.$ $\left.0.33, S D=0.095 ; M_{\mathrm{US}}=0.25, S D=0.072\right), t(112)=4.71, p<$ .001 , than when participants judged Lee $\left(M_{\text {China }}=0.29, S D=\right.$ $\left.0.089 ; M_{\mathrm{US}}=0.24, S D=0.078\right), t(112)=3.05, p<.001$.

\section{Relationship Between Entitativity and Group-Personality Consistency}

The next set of analyses focused on the relationship between perceptions of entitativity and personality consistency for the national groups. For the group Chinese, perceptions of entitativity were positively related to personality consistency in the total sample, $r=.32, p<.001$. This association was strong and positive for both American participants, $r=.64, p<.001$, and Chinese participants, $r=.41, p<.001$. Likewise, for the group Americans, perceptions of entitativity were positively related to personality consistency in the total sample, $r=.32, p<.001$. This association was moderate and (marginally) significant among American participants, $r=.26, p=.07$, but relatively weak among Chinese participants, $r=.09, n s$. Hence, groups that were seen as more cohesive entities also tended to be ascribed a more internally consistent personality, and this was generally true for both Chinese and American perceivers.

As outlined earlier, the ANOVA results showed that Chinese participants rated the target group Americans as more entitative and as having a more internally consistent personality than did American participants. To determine whether cultural differences in group-personality consistency could be explained by perceptions of entitativity, we conducted a mediational analysis. First, the consistency scores were regressed on culture $(b=.46, p<.001)$. Next, the mediator (entitativity) was regressed on culture $(b=.40$, $p<.001)$. Finally, the consistency scores were regressed on culture and entitativity simultaneously, and there was a marginally significant drop in the association between culture and consistency ( $b=.40, p<.001$; Sobel test, $\Delta b=.06, p=.097$ ). These findings show that perceptions of entitativity account, in part, for the observed cultural differences in personality consistency. Mediational analyses were not conducted for the target group Chinese, because culture was not significantly related to the criterion $(b=$ $-.04, n s)$.

\section{Discussion}

A number of factors influence entitativity judgments, including culturally based epistemic beliefs about the nature of social groups, the perceiver's motives and goals, ingroup/outgroup distinctions, and so on. Paralleling the results of Study 2, and in accordance with an entitative view of groups, Chinese participants generally perceived the target groups as more entitative and as having more internally consistent personalities than did American participants. These main effects of culture were moderated, however, by the ingroup/outgroup status of the perceiver, such that Chinese participants tended to rate higher entitativity and personality consistency in outgroups than ingroups, whereas these effects were not manifested by American participants.

It is noteworthy that the Chinese participants perceived the individual group members as having more internally consistent personalities than did Americans. This finding may seem somewhat surprising, given the Western tendency to see the individual as the perceptual unit of analysis. However, in the present study, the individuals were clearly identified as members of their national groups (e.g., "Lee/Xiaoming is a Chinese college student") and, hence, were likely perceived as group members rather than as separate, unique individuals. 
It is important to note that, although the Chinese participants generally perceived the national groups as more entitative and as having more consistent personalities, they did not have more negative evaluations of the target groups than did Americans, paralleling the results of Study 2. The Chinese participants saw the groups and their members as having clear dispositional qualities, but they were not more likely to hold prejudicial attitudes toward the groups.

In sum, our findings show that Chinese draw more internally consistent inferences about the personality characteristics of social groups and representative group members than do Americans. The mediational analyses indicate that perceptions of group entitativity account partly for these findings. For three of the four groups examined in Studies 2 and 3, perceptions of entitativity accounted for a significant (or marginally significant) percentage of the cultural variation in perceptions of group-personality consistency.

\section{General Discussion}

Our research makes a novel contribution to the cross-cultural, entitativity, and stereotyping literatures by demonstrating that Chinese rate a variety of social groups as more entitative and, as a result, perceive social groups as having more internally consistent personalities than do Americans. We reasoned that, in the absence of moderating contextual or individuating information, people would rely on their epistemic beliefs about the nature of groups when making dispositional judgments. In mainland China and other highly collectivist cultures, these epistemic beliefs emphasize the entitative, agentic nature of groups (Bond, 1986; Su et al., 1999; Triandis, 1995).

Do Chinese, then, stereotype more than do Americans? Stereotypes and stereotyping are broad constructs that have been conceptualized and measured in myriad ways. In its most basic form, a stereotype can be defined as "a cognitive structure that contains a perceiver's knowledge, beliefs, and expectancies about a human group" (Hamilton \& Trolier, 1986, p. 133). Stereotypes have been further conceptualized as both individual and consensual beliefs about the characteristics of a social group; both idiosyncratic and culturally shared cognitive representations are thought to be important to stereotype assessment (see Stangor \& Schaller, 2000). Given the theoretical complexity of this topic, it is not surprising that stereotyping, or the ascription of attributes to a group and its members, has been quantified through numerous methods, including adjective checklists, extremity/strength ratings, card-sorting tasks, percentage ratings, and diagnostic ratios (see Stangor \& Lange, 1994). A distinction can also be drawn between group-level stereotyping (the ascription of a unique disposition to a social group) and individual-level stereotyping (the ascription of attributes to a person on the basis of his or her group membership).

In our studies, the Chinese participants did stereotype more than Americans, on the basis of two measures of stereotyping. Classic stereotyping measures present participants with a list of culturally shared attributes, such as good at math for the group Asians, and then assess extremity. In Study 1, we employed a classic measure of individual-level stereotyping: extremity/strength ratings on a set of attributes that were established, through pretesting, as consensually stereotypical of the group. In Studies 2 and 3, we operationalized group-level stereotyping as the extent to which participants ascribed a coherent disposition (i.e., an internally consistent set of attributes) to the target groups. We sought to measure the extent to which participants held a definite and unambiguous group impression, and we reasoned that this could be quantified through consistency scores. If a group is thought to possess a large amount of Quality A, then presumably the group should possess a small amount of Quality Not-A. (A perceiver can hardly be said to hold a clear, stereotypic group impression if he or she strongly endorses both a trait and its semantic opposite as characteristic of a group.) Notably, this consistency index differs from traditional stereotyping instruments in two respects. First, the measure is idiographic rather than consensual (i.e., the content of the group disposition varies across participants), and second, it assesses internal consistency in a person's beliefs, as well as extremity. Across all three studies, Chinese participants made more internally consistent and extreme ratings of the groups and their members than did Americans. ${ }^{10}$

\section{Alternative Explanations}

One might argue that these cultural differences in grouppersonality consistency and stereotyping are simply due to cultural variation in a variety of factors, including the tendency to differentiate stimuli; in response style/scale usage; in conscientiousness and susceptibility to experimenter demand; or in social desirability biases. We consider each of these possibilities in turn.

\section{Differentiation in Judgment}

It is possible that the Chinese participants were more willing to make fine-grained and differentiated ratings among stimuli than were Americans. In Study 1, Chinese participants distinguished more between the Snoets and Frints. In Studies 2 and 3, they made more differentiated dispositional inferences than did Americans. Perhaps Chinese are simply more inclined to differentiate among stimuli. However, considerable past research has shown that Chinese tend to be more moderate than Americans, not more extreme, when making judgments. Mainland Chinese generally favor the "middle way" and demonstrate less disconfirmation bias, group polarization, and need for self-verification relative to Americans (Peng \& Nisbett, 1999; Spencer-Rodgers, Boucher, et al., 2007). Thus, rather than a tendency for Chinese to make more differentiated judgments, previous research has documented the opposite inclination.

\section{Response Style and Scale Usage}

Another possibility involves cultural differences in response style. As outlined above, East Asians have tended to show a moderacy bias in their scale usage (C. Chen, Lee, \& Stevenson, 1995; Kuroda, Hayashi, \& Suzuki, 1986; Zax \& Takahashi, 1967),

\footnotetext{
${ }^{10} \mathrm{We}$ conducted an additional analysis to evaluate the appropriateness of the consistency index as a measure of stereotyping. For each of the 28 attributes, we computed extremity scores by taking the absolute value of the deviation from the midpoint of the scale. We then computed, for each participant, the mean deviation score across the 28 attributes. For each target group and cultural group, separately, we correlated this extremity index with the consistency index. The extremity indices were highly correlated with the consistency indices, with $r$ s ranging from .82 to .91 .
} 
and one might speculate that this cultural difference would give rise to the higher consistency scores among Chinese participants in Studies 2 and 3. It is important to note, however, that this potential cultural bias would have worked against our main hypotheses. Research participants who were inclined to circle items at the midpoint of the scale would have obtained lower scores on the consistency index than would those who circled items at the endpoints. For example, rating a group as 5 on outgoing and 5 on shy (1-9 scale) yields a consistency score of .03, whereas rating a group as 8 on outgoing and 2 on shy (or vice versa) yields a higher consistency score of .42.

Another possibility is that Chinese participants acquiesce more, relative to Americans. Perhaps Chinese participants tend to endorse items without regard for content, thus explaining why they showed stronger trait inferences than did the American participants in Study 1 and more consistent dispositional inferences in Studies 2 and 3. However, such a bias would presumably have manifested in all judgments, which did not happen. In Study 1, there were no cultural differences on the nonstereotypical attribute ratings- only on the stereotypical ones - and in Studies 2 and 3, a tendency to acquiesce would have undermined the consistency index derived from opposing traits.

\section{Conscientiousness and Demand Characteristics}

One might also argue that the Chinese college students were more attentive and conscientious research participants, relative to Americans. They may have been more careful in their responses and more attentive to stimuli that demanded different responses. Could this explain why the Chinese participants distinguished more among the group targets and contrasting traits than Americans did? This argument assumes that either (a) the Chinese participants interpreted the tasks as requiring differentiation, or (b) careful and attentive Chinese participants would have been inclined to make more differentiated judgments. However, the Chinese participants could just as easily have interpreted the tasks as requiring uniformity in one's responses, and a careful and attentive Chinese participant would likely be motivated to provide moderate responses that represent a compromise between extremes, rather than differentiated responses. This would be in keeping with a tendency to avoid extreme positions and to approach conceptual issues dialectically (Peng \& Nisbett, 1999; Spencer-Rodgers \& Peng, 2004).

Most important, in earlier studies that we conducted using a very similar methodology but different targets, the pattern of cultural differences was very different from the findings reported here. These earlier studies were conducted as part of an investigation into cultural differences in perceptions of the self and close others. The participant samples were very similar to those employed in Studies 2 and 3 and consisted of Chinese students at Peking University and students of European descent at UC Berkeley and the University of Victoria, British Columbia, Canada. Participants rated themselves or their closest family member (an ingroup member) on the exact same contradictory trait pairs used in Studies 2 and 3 of the present research, and their responses were calculated via the same consistency formula (NAM method) and a similar procedure to that used in the present studies. The results showed that the Chinese participants $(M=.14, S D=.079)$ showed significantly less consistency (or greater ambivalence) in their self ratings than did North American participants $(M=.21, S D=$ $.080), F(1,122)=21.81, p<.001$. Likewise, Chinese participants $(M=.19, S D=.092)$ exhibited less consistency in their ratings of their family members than did the North Americans $(M=.24$, $S D=.13), F(1,70)=3.94, p=.05$.

If the tendency of Chinese participants to make stronger consistency judgments is domain specific (holding for perceptions of outgroups and their members but not for the self and ingroup members), we can further discount cultural differences in conscientiousness or demand characteristics as alternative explanations for our findings. It seems unlikely that the Chinese participants in these studies could have surmised that consistency was expected of them in one domain but that ambivalence was required of them in the others.

\section{Social Desirability}

One might also wonder whether cultural differences in social desirability could account for our findings. Perhaps the American participants were responding in a more socially desirable manner than the Chinese participants and were therefore avoiding endorsing stereotypes about social groups. However, if anything, East Asians (participants from mainland China, Hong Kong, Singapore, Thailand, Taiwan, and Japan) have been shown to be more concerned with social desirability (Middleton \& Jones, 2000) and impression management (Lalwani, Shavitt, \& Johnson, 2006) than have Americans. Moreover, to help alleviate this concern, we employed fictitious and culturally neutral groups in Studies 1 and 2 and a relatively unobtrusive measure of dispositional inference in Studies 2 and 3, thus reducing the likelihood that socialdesirability concerns were salient to participants in either culture.

In sum, the cross-cultural differences in dispositional and stereotypic inferences revealed in our studies are not readily explained in terms of historical contexts, prior social contact, or ingroup favoritism, nor by lower-level explanations involving styles of responding in experimental situations. Instead, they are consistent with research demonstrating that Chinese participants are more likely to infer dispositions when the behavioral unit is a group rather than an individual (Menon et al., 1999). They are also consistent with the notion that Chinese perceive social groups as having greater causal agency and dispositional qualities (Menon et al., 1999) than do Americans. Of course, further research is needed to determine whether our findings extend to members of other East Asian cultures, such as Japanese and Koreans, as well as to other American ethnic groups. Both samples consisted of urban, middleclass college students from relatively elite universities. Replications with other samples would be beneficial.

\section{Implications for Culture Research}

Our findings are particularly striking in light of previous research showing that Chinese are more dialectical than are Americans (Peng \& Nisbett, 1999; Spencer-Rodgers, Williams, \& Peng, 2007). Members of East Asian, Confucian-based societies, such as China, Japan, and Korea, possess folk epistemologies that emphasize tolerance of contradiction, the expectation of change, and cognitive holism (Peng \& Nisbett, 1999). East Asians exhibit less internal consistency than do North Americans in their emotions (Schimmack, Oishi, \& Diener, 2002), identities (Suh, 2002), val- 
ues (Choi \& Choi, 2002), self-conceptions (Spencer-Rodgers, Williams, \& Peng, 2007), and self-evaluations (Spencer-Rodgers, Peng, Wang, \& Hou, 2004). Given a proclivity to tolerate contradiction, it seems counterintuitive that our Chinese participants would rate social groups and their members more extremely and as having more internally consistent personalities than American participants would. Indeed, one might speculate, in light of the previous cross-cultural research on this topic, that the "search for consistency" is not a universal human motive.

We contend instead that the consistency motive is universal but may be expressed somewhat differently among Americans than among mainland Chinese. Cross-cultural research is increasingly showing that, although there are clearly important cultural differences in the manifestation of various psychological phenomena, many basic psychological processes are pancultural. Several fundamental processes known to operate at the individual or self level in Western, individualistic cultures have been shown to function at the group or social level in East Asian, collectivist ones (Morris et al., 2001). For instance, the attribution of behavior to stable dispositions seems to be a universal mechanism with cultural variations, such that, in North America, the dispositional actor is more apt to be an individual, whereas in China, the actor is more likely to be a social group (Menon et al., 1999). Likewise, the desire to enhance personally meaningful objects (e.g., the self in North America; the ingroup in East Asia) also is apparently a pancultural motivation with significant cultural manifestations (Endo, 1995; Heine \& Hamamura, 2007; Sedikides, Gaertner, \& Toguchi, 2003). Although Japanese do not experience cognitive dissonance with regard to decisions made for the self (Heine \& Lehman, 1997), they do so in broader social contexts-namely, for decisions made for an important other (Hoshino-Browne et al., 2005).

The need for consistency may be another fundamental psychological motive that operates differently in East Asian and Western societies. A great deal of Western research shows that people possess a strong need to see themselves as consistent (Festinger, 1957; Swann, Rentfrow, \& Guinn, 2003). The search for consistency is the cornerstone of a multitude of Western psychological theories, including balance (Heider, 1958), cognitive dissonance (Festinger, 1957), and self-verification theories (Swann et al., 2003). Consistency and stability in the individual is highly valued and culturally prescribed in Western cultures (Markus \& Kitayama, 1991; Suh, 2002; Swann et al., 2003). In East Asian, collectivist ones, however, consistency and stability are sought not in the individual but in the social fabric of human life: in stable groups and institutions, in enduring social customs and traditions, and in the complex web of interpersonal relationships that are based on interdependence and hierarchical social arrangements (Nisbett, 2003). Paralleling other cross-cultural findings, perhaps the need for consistency, measured here in the form of perception of personality traits, is manifested more strongly at the group or social level than at the individual or self level among Chinese participants. In our view, therefore, it is perfectly plausible that the Chinese participants should view groups (more so than individuals) as cohesive entities with stable, coherent, internally driven behaviors, whereas Americans should see individuals (more so than groups) in this manner. This may readily explain why Chinese are dialectical about the self and do not commit the fundamental attribution error but see groups as cohesive entities with internally consistent personalities and stereotypic attributes.

\section{Implications for Entitativity Research}

Our research has identified both cultural differences and similarities in perceptions of group entitativity. Chinese participants rated a variety of social groups as more entitative than did Americans, suggesting that there is cross-cultural variation in basic group perception. Yet among both Chinese and Americans, perceptions of group entitativity tended to be associated with more consistent dispositional inferences. The average correlation between group entitativity and perceived personality consistency across the target groups was $r=.31$ among Chinese participants and $r=.39$ among Americans. These average correlations do not differ significantly from each other, $z<1, n s$, suggesting that the strength of the association was roughly the same for Chinese and Americans. Thus, a principal pancultural consequence of perceiving social groups as cohesive, uniform entities appears to be increased dispositional and stereotypic judgments. Prior research has shown that Westerners are more likely to make dispositional inferences (Susskind et al., 1999; Yzerbyt et al., 1998) and to hold stereotypic beliefs about high- than low-entitative targets (Spencer-Rodgers, Hamilton, \& Sherman, 2007). Although further research with other samples is certainly warranted, our studies are the first to suggest that the relation between group entitativity and stereotyping might be culturally universal.

\section{Implications for Intergroup-Relations Research}

We posited that, in the absence of moderating contextual information, Chinese participants would be more vulnerable to stereotyping than would Americans, because they perceive groups as more entitative units with core personalities, reliable traits, and an agentic will. However, as evidenced in their evaluative ratings, our Chinese participants were not more prejudiced than the Americans.

An intriguing solution to this puzzle is the possibility that the link between stereotyping and prejudice is weaker in Chinese than American samples. That is, stereotyping may stem from different sources and have different outcomes among East Asians (Y. Chen et al., 2002). For example, for Chinese, stereotyping might derive from epistemic beliefs about the basic nature and function of social groups (e.g., the belief that groups have stable personalities or the belief that individuals adopt the characteristics of the groups to which they belong); for Americans, stereotyping may rest more heavily on the need for positive differentiation and the enhancement of self-esteem (e.g., the need to see one's ingroup as better than the outgroup or the need to derive a sense of self-worth from one's group memberships). These differences in the roots of stereotypes may lead to differences in the relation between stereotyping and prejudice. Similarly, some scholars have argued that East Asians are generally less concerned with intergroup phenomena, such as differentiation between ingroups and outgroups, and focus instead on intragroup phenomena, such as the complex network of interrelationships within the ingroup (Yuki, 2003). These are intriguing questions that need to be explored in future research.

\section{Implications for Causal Attribution}

At first glance, the present research in the domain of culture and stereotyping appears to conflict with previous work on culture and 
causal attribution, which has repeatedly shown that East Asians are less likely than Westerners to apply dispositional traits to individuals (Choi et al., 1999; F. Lee et al., 1996; Miller, 1984; Morris \& Peng, 1994). The current studies focused on cultural differences in stereotyping processes and do not speak directly to cultural variation in causal attribution for social behavior. But rather than contradicting previous attribution work, our findings may instead help to clarify the circumstances under which cultural differences in trait attribution might be found. In the absence of salient situational or individuating information, Chinese might be more willing to rely on group membership as a causal explanation for social behavior, as a result of a tendency to view social groups as entitative with stereotypic personalities (for a similar argument about the interplay between dispositional inference and causal attribution, see Hamilton, 1998).

It is important to note that we do not make the claim, nor do we test the hypothesis, that Chinese will stereotype more than will Americans, even in the presence of moderating information. In Study 1, the Chinese participants stereotyped more than did Americans; however, they were not provided with any details about situational influences or the unique, personal attributes of the targets. Rather, they were simply asked to imagine a social encounter with a Snoet or Frint and to make a dispositional inference. The target's group membership was the only obvious source of dispositional information, and Chinese participants were more willing than American participants to use that knowledge in their judgments. Of course, this is often the state of affairs in the real world: We develop impressions of people quickly, without access to information about their personalities or the situational factors that might be influencing their behaviors. Further research is needed to determine whether Chinese stereotype more or less than do Americans when individuating and contextual information are available and salient. The potential avenues of future research outlined here will expand our understanding of cultural differences in stereotyping processes, beyond a description of stereotype content.

\section{References}

Abelson, R. P., Dasgupta, N., Park, J., \& Banaji, M. R. (1998). Perception of the collective other. Personality and Social Psychology Review, 2, 243-250.

Alexander, M. G., Brewer, M. B., \& Hermann, R. K. (1999). Images and affect: A functional analysis of out-group stereotypes. Journal of Personality and Social Psychology, 77, 78-93.

Bond, M. H. (Ed.). (1986). The psychology of the Chinese people. Hong Kong: Oxford University Press.

Brewer, M. B., Hong, Y., \& Li, Q. (2004). Dynamic entitativity: Perceiving groups as actors. In V. Yzerbyt, C. Judd, \& O. Corneille (Eds.), The psychology of group perception: Contributions to the study of homogeneity, entitativity, and essentialism (pp. 25-38). New York: Psychology Press.

Byrne, B. M. (2001). Structural equation modeling with AMOS: Basic concepts, applications and programming. Mahwah, NJ: Erlbaum.

Castano, E., Yzerbyt, V. Y., \& Bourguignon, D. (2003). We are one and I like it: The impact of ingroup entitativity on ingroup identification. European Journal of Social Psychology, 33, 735-754.

Chen, C., Lee, S.-Y., \& Stevenson, H. (1995). Response style and crosscultural comparison of rating scales among East Asian and North American students. Psychological Science, 6(3), 170-175.

Chen, Y., Brockner, J., \& Chen, X. (2002). Individual-collective primacy and ingroup favoritism: Enhancement and protection effects. Journal of Experimental Social Psychology, 38, 482-491.

Chiu, C., Dweck, C. S., Tong, Y., \& Fu, J. (1997). Implicit theories and conceptions of morality. Journal of Personality and Social Psychology, 73, 923-940.

Chiu, C., Hong, Y., \& Dweck, C. S. (1997). Lay dispositionism and implicit theories of personality. Journal of Personality and Social Psychology, 73, 19-30.

Chiu, C., Morris, M. W., Hong, Y., \& Menon, T. (2000). Motivated cultural cognition: The impact of implicit cultural theories on dispositional attribution varies as a function of need for closure. Journal of Personality and Social Psychology, 78, 247-259.

Choi, I., \& Choi, Y. (2002). Culture and self-concept flexibility. Personality and Social Psychology Bulletin, 28, 1508-1517.

Choi, I., \& Nisbett, R. E. (1998). Situational salience and cultural differences in the correspondence bias and actor-observer bias. Personality and Social Psychology Bulletin, 24, 949-960.

Choi, I., Nisbett, R. E., \& Norenzayan, A. (1999). Causal attribution across cultures: Variation and universality. Psychological Bulletin, 125, 47-63.

Cousins, S. D. (1989). Culture and self-perception in Japan and the United States. Journal of Personality and Social Psychology, 56, 124-131.

Crawford, M. T., Sherman, S. J., \& Hamilton, D. L. (2002). Perceived entitativity, stereotype formation, and the interchangeability of group members. Journal of Personality and Social Psychology, 83, 10761094.

Crump, S. A., Hamilton, D. L., Sherman, S. J., \& Thakker, V. (2005). Group entitativity and similarity: Their differing patterns in perceptions of groups. Unpublished manuscript.

Devine, P. (1989). Stereotypes and prejudice: Their automatic and controlled components. Journal of Personality and Social Psychology, 56, $5-18$.

Endo, Y. (1995). A false modesty/other-enhancing bias among Japanese. Psychologia: An International Journal of Psychology in the Orient, 38(2), 59-69.

Festinger, L. (1957). A theory of cognitive dissonance. Stanford, CA: Stanford University Press.

Fiske, S. T. (1998). Stereotyping, prejudice, and discrimination. In D. Gilbert, S. T. Fiske, \& G. Lindzey (Eds.), Handbook of social psychology (4th ed., Vol. 2, pp. 357-411). Boston: McGraw-Hill.

Fiske, S. T., Cuddy, A. J., Glick, P., \& Xu, J. (2002). A model of (often mixed) stereotype content: Competence and warmth, respectively, follow from perceived status and competition. Journal of Social Issues, 60, 701-718.

Hamilton, D. L. (1988). Causal attribution viewed from an information processing perspective. In D. Bar-Tal \& A. W. Kruglanski (Eds.), The social psychology of knowledge (pp. 359-385). Cambridge, England: Cambridge University Press.

Hamilton, D. L. (1998). Dispositional and attributional inferences in person perception. In J. M. Darley \& J. Cooper (Eds.), Attribution and social interaction: The legacy of Edward E. Jones (pp. 99-114). Washington, DC: American Psychological Association.

Hamilton, D. L., \& Sherman, S. J. (1996). Perceiving persons and groups. Psychological Review, 103, 336-355.

Hamilton, D. L., Sherman, S. J., \& Castelli, L. (2002). A group by any other name: The role of entitativity in group perception. In W. Stroebe \& M. Hewstone (Eds.), European review of social psychology (Vol. 12, pp. 139-166). New York: Wiley.

Hamilton, D. L., Sherman, S. J., \& Lickel, B. (1998). Perceiving social groups: The importance of the entitativity continuum. In C. Sedikides, J. Schopler, \& C. A. Insko (Eds.), Intergroup cognition and intergroup behavior (pp. 47-74). Mahwah, NJ: Erlbaum.

Hamilton, D. L., Sherman, S. J., \& Spencer-Rodgers, J. (2004). Perceiving the groupness of groups: Entitativity, homogeneity, essentialism, and stereotyping. In V. Yzerbyt, C. Judd, \& O. Corneille (Eds.), The psy- 
chology of group perception: Contributions to the study of homogeneity, entitativity, and essentialism (pp. 39-60). Brighton, United Kingdom: Psychology Press.

Hamilton, D. L., \& Trolier, T. K. (1986). Stereotypes and stereotyping: An overview of the cognitive approach. In J. F. Dovidio \& S. L. Gaertner (Eds.), Prejudice, discrimination, and racism (pp. 127-163). San Diego, CA: Academic Press.

Heider, F. (1958). The psychology of interpersonal relations. New York: Wiley.

Heine, S. J., \& Hamamura, T. (2007). In search of East Asian selfenhancement. Personality and Social Psychology Review, 11(1), 4-27.

Heine, S., \& Lehman, D. (1997). Culture, dissonance, and self-affirmation. Personality and Social Psychology Bulletin, 23, 389-400.

Hong, Y., Coleman, J., Chan, G., Wong, R. Y., Chiu, C., Hansen, I. G., et al. (2004). Predicting intergroup bias: The interactive effects of implicit theory and social identity. Personality and Social Psychology Bulletin, 30, 1035-1047.

Hoshino-Browne, E., Zanna, A. S., \& Spencer, S. J. (2005). On the cultural guises of cognitive dissonance: The case of Easterners and Westerners. Journal of Personality and Social Psychology, 89, 294-310.

Judd, C. M., \& Bartsch, R. A. (1995). Cats, dogs, and the OH effect: A reply to Simon and to Haslam and Oakes. European Journal of Social Psychology, 25, 477-480.

Kashima, Y. (2001). Culture and social cognition: Towards a social psychology of cultural dynamics. In D. Matsumoto (Ed.), Handbook of culture and psychology (pp. 325-360). New York: Oxford University Press.

Kashima, Y. (2004). Culture, communication, and entitativity: A social psychological investigation of social reality. In V. Yzerbyt, C. Judd, \& O. Corneille (Eds.), The psychology of group perception: Contributions to the study of homogeneity, entitativity, and essentialism (pp. 257-273). Brighton, United Kingdom: Psychology Press.

Kashima, Y., Kashima, E. S., Chiu, C., Farsides, T., Gelfand, M. J., Hong, Y., et al. (2004). Culture, essentialism, and agency: Are individuals universally believed to be more real entities than groups? European Journal of Social Psychology, 35(2), 1-23.

Kashima, Y., Kashima, E. S., Kim, U., \& Gelfand, M. (2006). Describing the social world: How is a person, a group, and a relationship described in the East and the West? Journal of Experimental Social Psychology, 42, 388-396

Kashima, Y., Siegal, M., Tanaka, K., \& Kashima, E. S. (1992). Do people believe behaviours are consistent with attitudes? Towards a cultural psychology of attribution processes. British Journal of Social Psychology, 31(2), 111-124.

Koomen, W., \& Bähler, M. (1996). National stereotypes: Common representations and ingroup favouritism. European Journal of Social Psychology, 26(2), 325-331.

Kuroda, Y., Hayashi, C., \& Suzuki, T. (1986). The role of language in cross-national surveys: American and Japanese respondents. Applied Stochastic Model and Data Analysis, 2, 43-59.

Lalwani, A. K., Shavitt, S., \& Johnson, T. (2006). What is the relationship between cultural orientation and socially desirable responding? Journal of Personality and Social Psychology, 90, 165-178.

Lee, F., Hallahan, M., \& Herzog, T. (1996). Explaining real-life events: How culture and domain shape attributions. Personality and Social Psychology Bulletin, 22, 732-741.

Lee, Y., \& Ottati, V. (1993). Determinants of in-group and out-group perceptions of heterogeneity: An investigation of Sino-American stereotypes. Journal of Cross-Cultural Psychology, 24, 298-313.

Lee, Y., \& Ottati, V. (1995). Perceived in-group homogeneity as a function of group membership salience and stereotype threat. Personality and Social Psychology Bulletin, 21, 610-619.

Levy, S. R., \& Dweck, C. S. (1999). The impact of children's static vs. dynamic conceptions of people on stereotype formation. Child Development, 70, 1163-1180.

Levy, S. R., Stroessner, S. J., \& Dweck, C. (1998). Stereotype formation and endorsement: The role of implicit theories. Journal of Personality and Social Psychology, 74, 1421-1436.

Maass, A., Karasawa, M., Politi, F., \& Suga, S. (2006). Do verbs and adjectives play different roles in different cultures? A cross-linguistic analysis of person representation. Journal of Personality and Social Psychology, 90, 734-750.

Marín, G., \& Salazar, J. M. (1985). Determinants of hetero- and autostereotypes: Distance, level of contact, and socioeconomic development in seven nations. Journal of Cross-Cultural Psychology, 16, 403-422.

Markus, H. R., \& Kitayama, S. (1991). Culture and the self: Implications for cognition, emotion, and motivation. Psychological Review, 98, 224 253.

Masuda, T., \& Nisbett, R. E. (2001). Attending holistically versus analytically: Comparing the context sensitivity of Japanese and Americans. Journal of Personality and Social Psychology, 81, 922-934.

McAndrew, F. T., Akande, A., Bridgstock, R., Mealey, L., Gordon, S. C., Scheib, J. E., et al. (2000). A multicultural study of stereotyping in English-speaking countries. Journal of Social Psychology, 140, $487-$ 502.

Menon, T., Morris, M. W., Chiu, C., \& Hong, Y. (1999). Culture and the construal of agency: Attribution to individual versus group dispositions. Journal of Personality and Social Psychology, 76, 701-717.

Middleton, K. L., \& Jones, J. L. (2000). Socially desirable response sets: The impact of country culture. Psychology and Marketing, 17(2), 149163.

Miller, J. G. (1984). Culture and the development of everyday social explanation. Journal of Personality and Social Psychology, 46, 961978.

Morris, M. W., Menon, T., \& Ames, D. R. (2001). Culturally conferred conceptions of agency: A key to social perception of persons, groups, and other actors. Personality and Social Psychology Review, 5, 169182.

Morris, M. W., \& Peng, K. (1994). Culture and cause: American and Chinese attributions for social and physical events. Journal of Personality and Social Psychology, 67, 949-971.

Nisbett, R. E. (2003). The geography of thought: How Asians and Westerners think differently . . and why. New York: Free Press.

Oyserman, D., Coon, H., \& Kemmelmeier, M. (2002). Rethinking individualism and collectivism: Evaluation of theoretical assumptions and meta-analyses. Psychological Bulletin, 128, 3-72.

Park, B., \& Rothbart, M. (1982). Perception of out-group homogeneity and levels of social categorization: Memory for the subordinate attributes of in-group and out-group members. Journal of Personality and Social Psychology, 42, 1051-1068.

Peng, K., \& Nisbett, R. E. (1999). Culture, dialectics, and reasoning about contradiction. American Psychologist, 54, 741-754.

Poppe, E. (2001). Effects of changes in GNP and perceived group characteristics on national and ethnic stereotypes in Central and Eastern Europe. Journal of Applied Social Psychology, 31, 1689-1708.

Priester, J. R., \& Petty, R. E. (1996). The gradual threshold model of ambivalence: Relating the positive and negative attitudes to subjective ambivalence. Journal of Personality and Social Psychology, 71, 431449.

Ross, L. (1977). The intuitive psychologist and his shortcomings: Distortions in the attribution process. In L. Berkowitz (Ed.), Advances in experimental social psychology (pp. 173-220). New York: Academic Press.

Rothbart, M., \& Park, B. (2004). The mental representation of social categories: Category boundaries, entitativity, and essentialism. In V. Yzerbyt, C. Judd, \& O. Corneille (Eds.), The psychology of group 
perception: Contributions to the study of homogeneity, entitativity, and essentialism (pp. 79-100). New York: Psychology Press.

Schimmack, U., Oishi, S., \& Diener, E. (2002). Cultural influences on the relation between pleasant emotions and unpleasant emotions: Asian dialectic philosophies or individualism-collectivism? Cognition \& Emotion, 16, 705-719.

Scott, W. A. (1966). Brief report: Measures of cognitive structure. Multivariate Behavior Research, 1, 391-395.

Sedikides, C., Gaertner, L., \& Toguchi, Y. (2003). Pancultural selfenhancement. Journal of Personality and Social Psychology, 84, 60-79.

Sherman, S. J., Hamilton, D. L., \& Lewis, A. (1999). Perceived entitativity and the social identity value of group membership. In D. Abrams \& M. Hogg (Eds.), Social identity and social cognition (pp. 80-110). London: Blackwell.

Simon, B. (1992). The perception of ingroup and outgroup homogeneity: Re-introducing the intergroup context. In W. Stroebe \& M. Hewstone (Eds.), European review of social psychology (Vol. 3, pp. 1-30). Chichester, United Kingdom: Wiley.

Smith, P. B. (2004). Acquiescent response bias as an aspect of cultural communication style. Journal of Cross-Cultural Psychology, 35(1), 5061.

Spencer-Rodgers, J., Boucher, H. C., Mori, S., Wang, L., \& Peng, K. (2007). The dialectical self-concept: Contradiction, change, and holism in East Asian cultures. Unpublished manuscript.

Spencer-Rodgers, J., Hamilton, D. L., \& Sherman, S. J. (2007). The central role of entitativity in stereotypes of social categories and task groups. Journal of Personality and Social Psychology, 92, 369-388.

Spencer-Rodgers, J., \& Peng, K. (2004). The dialectical self: Contradiction, change, and holism in the East Asian self-concept. In R. M. Sorrentino, D. Cohen, J. M. Olsen, \& M. P. Zanna (Eds.), Culture and social behavior: The Ontario Symposium (Vol. 10, pp. 227-249). Mahwah, NJ: Erlbaum.

Spencer-Rodgers, J., Peng, K., Wang, L., \& Hou, Y. (2004). Dialectical self-esteem and East-West differences in psychological well-being. Personality and Social Psychology Bulletin, 30, 1416-1432.

Spencer-Rodgers, J., Williams, M. J., \& Peng, K. (2007). How Asian folk beliefs of knowing affect the psychological investigation of cultural differences. In J. H. Liu, C. Ward, A. B. Bernardo, M. Karasawa, \& R. Fischer (Eds.), Progress in Asian social psychology (Vol. 6, pp. 261272). Seoul, South Korea: Asian Association of Social Psychology.

Stangor, C., \& Lange, J. E. (1994). Mental representations of social groups: Advances in understanding stereotypes and stereotyping. In M. P. Zanna (Ed.), Advances in experimental social psychology (Vol. 26, pp. 357416). San Diego, CA: Academic Press.

Stangor, C., \& Schaller, M. (2000). Stereotypes as individual and collective representations. In C. Stangor (Ed.), Stereotypes and prejudice: Essential readings (pp. 64-82). New York: Psychology Press.

Su, S. K., Chiu, C., Hong, Y., Leung, K., Peng, K., \& Morris, M. W. (1999). Self-organization and social organization: U.S. and Chinese constructions. In T. R. Smith, R. M. Kramer, \& O. P. John (Eds.), The psychology of the social self: Applied social research (pp. 193-222). Mahwah, NJ: Erlbaum.

Suh, E. M. (2002). Culture, identity consistency, and subjective well-being. Journal of Personality and Social Psychology, 83, 1378-1391.

Susskind, J., Maurer, K., Thakkar, V., Hamilton, D. L., \& Sherman, S. J. (1999). Perceiving individuals and groups: Expectancies, dispositional inferences, and causal attributions. Journal of Personality and Social Psychology, 76, 181-191.

Swann, W. B., Rentfrow, P., \& Guinn, J. (2003). Self-verification: The search for coherence. In M. Leary \& J. Tangney (Eds.), Handbook of self and identity (pp. 367-383). New York: Guilford.

Thompson, M., Zanna, M., \& Griffin, D., (1995). Let's not be indifferent about (attitudinal) ambivalence. In R. Petty \& J. Krosnick (Eds.), Attitude strength: Antecedents and consequences (pp. 361-386). Mahwah, NJ: Erlbaum.

Triandis, H. C. (1995). Individualism and collectivism. Boulder, CO: Westview Press.

Triandis, H. C., McCusker, C., \& Hui, C. H. (1990). Multimethod probes of individualism and collectivism. Journal of Personality and Social Psychology, 59, 1006-1020.

Turner, J. C., Hogg, M. A., Oakes, P., Reicher, S., \& Wetherell, M. (1987). Rediscovering the social group: A self-categorization theory. Oxford, United Kingdom: Blackwell.

Yuki, M. (2003). Intergroup connection versus intragroup relationships: A cross-cultural examination of social identity theory in North American and East Asian cultural contexts. Social Psychology Quarterly, 66(2), $166-183$.

Yzerbyt, V. Y., Castano, E., Leyens, J.-P., \& Paladino, M-P. (2000). The phenomenology of the ingroup: The interplay of identification, entitativity and overexclusion. In W. Stroebe \& M. Hewstone (Eds.), European review of social psychology (Vol. 11, pp. 257-295). Chichester, United Kingdom: Wiley.

Yzerbyt, V. Y., Corneille, O., \& Estrada, C. (2001). The interplay of subjective essentialism and entitativity in the formation of stereotypes. Personality and Social Psychology Review, 5, 141-155.

Yzerbyt, V. Y., Judd, C., \& Corneille, O. (Eds.). (2004). The psychology of group perception: Perceived variability, entitativity, and essentialism. New York: Psychology Press.

Yzerbyt, V. Y., Rocher, S. J., \& Schadron, G. (1997). Stereotypes as explanations: A subjective essentialistic view of group perception. In R. Spears, P. Oakes, N. Ellemers, \& A. Haslam (Eds.), The psychology of stereotyping and group life (pp. 20-50). London: Blackwell.

Yzerbyt, V. Y., Rogier, A., \& Fiske, S. T. (1998). Group entitativity and social attribution: On translating situational constraints into stereotypes. Personality and Social Psychology Bulletin, 24, 1089-1103.

Zax, M., \& Takahashi, S. (1967). Cultural influences on response style: Comparisons of Japanese and American college students. Journal of Social Psychology, 71(1), 3-10. 


\section{Appendix}

\section{Measure of Group Entitativity}

Participants in Studies 2 and 3 indicated agreement with these items using a 1 (not at all) to 9 (very) scale.

1. How cohesive is the group?

2. How important is the group to its members?

3. How organized is the group?

4. Overall, how similar are members of the group to each other?

5. To what extent do you think the members of the group feel that they are part of the group?

6. Some groups have the characteristics of a "group" more than others do. To what extent does this group qualify as a group?

7. Some groups possess a core personality; although there may be differences and similarities in their behaviors, underneath they are basically the same. To what extent does the group possess a core personality?

8. How variable are the behaviors of the group? (Reverse scored)

9. Some groups possess basic or fundamental qualities that do not seem to change much over time. Other groups possess qualities or characteristics that do change. How changeable are the characteristics of the group? (Reverse scored)
10. Some groups are conflicted; they are uncertain or unsure of their attitudes, values, and goals. Other groups' attitudes, values, and goals are definite and firm. How conflicted is the group? (Reverse scored)

11. To what extent is the group able to achieve its goals and make things happen (e.g., produce specific outcomes)?

12. Some groups are coherent; their attitudes, values, and goals seem to be harmonious and compatible. Other groups' attitudes, values, and goals seem to be incompatible or in disagreement. How coherent is the group?

13. Some groups' attitudes, values, and behaviors depend very much on where they are or who they are with. Other groups' attitudes, etc. are pretty much the same regardless of where they are or who they are with. How much do the attitudes, etc. of the group depend on where they are or who they are with? (Reverse scored)

14. Some groups have the characteristic of being distinctive or unique. That is, they do not share many qualities or characteristics with other groups. How distinctive is the group?

Received December 28, 2005 Revision received February 12, 2007 Accepted February 23, 2007 